\title{
What you see is what you hear: Twenty years of research using the Sound-Induced Flash Illusion
}

\author{
Rebecca J. Hirst ${ }^{\mathrm{a}, \mathrm{b}, *}$, David P. McGovern ${ }^{\mathrm{c}}$, Annalisa Setti ${ }^{\mathrm{d}}$, Ladan Shams ${ }^{\mathrm{e}}$, Fiona N. Newell ${ }^{\mathrm{a}}$ \\ ${ }^{a}$ School of Psychology and Institute of Neuroscience, Trinity College Dublin, Ireland \\ b The Irish Longitudinal Study on Ageing, Trinity College Dublin, Ireland \\ ${ }^{\text {c }}$ School of Psychology, Dublin City University, Dublin, Ireland \\ ${ }^{\mathrm{d}}$ School of Applied Psychology, University College Cork, Ireland \\ ${ }^{\mathrm{e}}$ Department of Psychology, Department of BioEngineering, Interdepartmental Neuroscience Program, University of California, Los Angeles, CA, USA
}

\section{A R T I C L E I N F O}

\section{Keywords:}

Sound-Induced Flash Illusion

Multisensory

Auditory-visual interactions

Crossmodal interactions

Visual illusion

Multisensory illusion

Optimal integration

Bayesian integration

\begin{abstract}
A B S T R A C T
In the Sound-Induced Flash Illusion (SIFI) sound dramatically alters visual perception, as presenting a single flash with two beeps results in the perception of two flashes. In this comprehensive review, we synthesise 20 years of research using the SIFI, from over 100 studies. We discuss the neural and computational principles governing this illusion and examine the influence of perceptual experience, development, ageing and clinical conditions. Convergent findings show that the SIFI results from optimal integration and probabilistic inference and directly reflects crossmodal interactions in the temporal domain. Its neural basis lies in early modulation of visual cortex by auditory and multisensory regions. The SIFI shows increasingly strong potential as an efficient tool for measuring multisensory processing. Greater harmonisation across studies is now required to maximise this potential. We therefore propose considerations for researchers relating to choice of stimulus parameters and signpost directions for future research.
\end{abstract}

\section{Introduction}

Our perception of the world results from the convergence of information from multiple senses. In most cases, sensory integration is beneficial to perception as it capitalises upon the most reliable information available across sensory channels. Presenting stimuli to multiple senses increases stimulus saliency (Noesselt et al., 2008; Odgaard et al., 2004; Stein et al., 1996) and perceived intensity (Stein et al., 1996), serving to enhance basic perceptual tasks such as target detection (Diederich and Colonius, 2004; Forster et al., 2002; Gondan et al., 2005; Lovelace et al., 2003; Nelson et al., 1998). However, in some cases, combining information across the senses can lead perception astray, resulting in illusions. Some classic examples are cases in which observers are presented with conflicting stimuli across modalities leading to well-known perceptual effects such as the ventriloquist effect (Howard and Templeton, 1966), visual capture (Hay et al., 1965; Rock and Victor, 1964), McGurk effect (McGurk and MacDonald, 1976), rubber hand illusion (Botvinick and Cohen, 1998) and the Colavita effect (Colavita, 1974; for review see Hirst et al., 2018a). In such examples, visual information overrides or alters the percept in another modality, suggesting that vision is the dominant sensory modality in humans.

In contrast to these earlier well-known multisensory illusions, the Sound-Induced Flash Illusion (SIFI), in which the rapid presentation of a single visual stimulus, a 'flash', with two auditory 'beeps' results in the perception of two flashes (Fig. 1a; Shams et al., 2000) demonstrates a radical alteration of visual perception by sound, even when there is no apparent ambiguity in the visual stimulus. Importantly, this illusion demonstrates that vision is not always the dominant modality in humans, but can be qualitatively altered by sound. Since its discovery, many studies have shown this illusion to be a promising measure of integration (Fig. 1b), with effective validity, robustness to a variety of parameters, and universality (Rosenthal et al., 2009; Shams et al., 2002). In a typical experiment participants tend to perceive the illusion in a large number of trials. However, this number can vary depending on experiment set up, with recent reports indicating the illusion occurs on around $50 \%$ of trials conducted by the individual (Keil, 2020) but several studies report more (Cecere et al., 2015; Shams et al., 2002).

The SIFI has shed light on the nature and mechanisms of human

Abbreviation: SIFI, Sound-Induced Flash illusion.

* Corresponding author at: Institute of Neuroscience, Trinity College Dublin, Ireland.

E-mail address: HirstR@tcd.ie (R.J. Hirst). 
multisensory perception as recently reviewed in Keil (2020). Perhaps due to the simple nature of the task, the paradigm has also been used to detect sensory processing differences across several clinical subgroups including autism (Foss-Feig et al., 2010; Kawakami et al., 2018; Keane et al., 2010; Stevenson et al., 2014; van Der Smagt et al., 2007), schizophrenia (Balz et al., 2016b; Ferri et al., 2018; Haß et al., 2017; Odegaard and Shams, 2017; Vanes et al., 2016), migraine (Brighina et al., 2015, 2014; Di Marco et al., 2015; Maccora et al., 2019), mild cognitive impairment (Chan et al., 2015), multiple sclerosis (Yalachkov et al., 2019), fall-prone older adults (Setti et al., 2014, 2011; Stapleton et al., 2014), hemispatial neglect (Bolognini et al., 2016), amblyopia (Narinesingh et al., 2017), monocular enucleation (Moro and Steeves, 2018) and hearing aid users (Gieseler et al., 2018). Very recently, the illusion has also been observed in rodents (Ito et al., 2019), opening up new avenues for translational models of multisensory perception using this paradigm.

We begin this review by discussing the theoretical context in which the SIFI falls. We then synthesise the existing literature to discuss the neural origins of the effect, findings in several sub-populations and the effect of various stimulus parameters on SIFI susceptibility. We aim to provide a timely, and thorough, update on almost 20 years of investigations based on the SIFI.

\subsection{Theoretical context: the flexible nature of multisensory processing}

The SIFI suggests that visual perception is modifiable by sound (Shams et al., 2002) and therefore challenges the traditional view in human perceptual science that vision dominates other senses, which may have lead to proportionally more research on vision than other sensory modalities (Hutmacher, 2019). The SIFI therefore represents an important milestone in a shift towards a more general, ethologically relevant, theory of human perception involving multisensory processing.

Several theories have been proposed to explain why one sense can dominate in some circumstances, whilst others dominate in others. The directed attention hypothesis proposes that the attended modality drives perception (Amedi et al., 2017; Welch and Warren, 1980). This theory would predict that biasing attention towards vision should reverse the SIFI. The SIFI is reported to occur even when participants are explicitly instructed to attend to either vision or audition (Odegaard et al., 2016). However, DeLoss et al. (2013) found that introducing a visual Go/No-Go task reduced SIFI effects, possibly due to biasing attention to visual targets. Andersen et al. (2004) found that instructing participants to attend to audition was not sufficient to reverse the SIFI, although concurrently lowering the intensity of the auditory stimulus to near threshold levels did reverse SIFI effects, such that vision influenced audition. These findings indicate that whereas attention alone may not modulate the SIFI, manipulating the reliability of information presented to each sense may influence SIFI perception.

The modality-appropriateness hypothesis suggests that the sense most appropriate to the given task drives perception (Welch and Warren, 1986). As such, vision tends to dominate in spatial judgements, whilst audition dominates temporal judgements, as a result of their respective spatial and temporal resolutions (e.g. McGovern et al., 2016a, 2016b). While this theory may explain the typical interactions between the modalities, it fails to predict behaviour when the stimuli in the 'dominant' modality are impoverished and unreliable (Alais and Burr, 2004).

Models based on the reliability of information in each sense e.g. maximum likelihood estimation model (Ernst and Banks, 2002; Ernst and Bülthoff, 2004) propose that sensory information is weighted according to its relative reliability and precision in a given task. However, such models assume that sensory signals are always fused even when there is a large conflict between the signals. Therefore, this approach cannot account for an absence of integration (i.e. segregation) or partial integration between the senses seen in the SIFI (Shams, 2012; Shams and Beierholm, 2011). Moreover, reliability models do not account for the role of prior knowledge or expectation on multisensory perception.

The SIFI can be considered a temporal numerosity judgment task, in which the task is to determine the number of visual events and/or auditory events. There are two types of prior knowledge/expectations that could influence perception in this task. One is the prior expectation for a given number of events (i.e. number of flashes/beeps). This prior can vary across individuals perhaps depending on their experience. For example, if an individual is frequently exposed to environments containing flashing lights (such as discos) or pulsating sounds (e.g., trucks beeping while reversing), this might induce the expectation of a higher number of perceptual events, resulting in a higher incidence of fission illusions (perceiving one flash as two when presented with two beeps). In line with this, informing participants to expect a larger proportion of single flash trials can decrease the illusion (Wang et al., 2019).

The second type of prior knowledge/bias that can influence perception is the expectation that auditory and visual stimuli share a common cause. This also varies across individuals and can be influenced by life experience, the experimental setup or experimenter instructions. For example, if prior experience favours the binding of auditory and visual stimuli (e.g. by extensive and repeated exposure to congruent a)

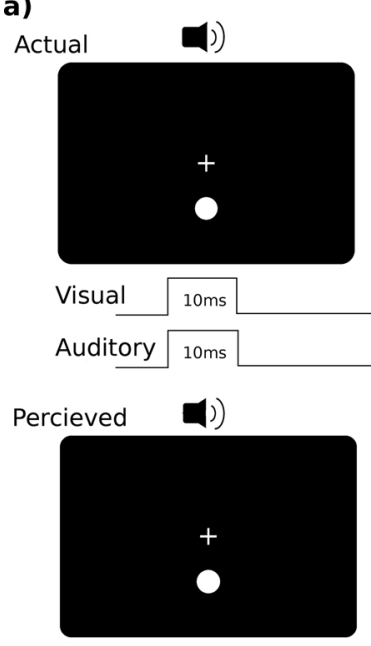

b)

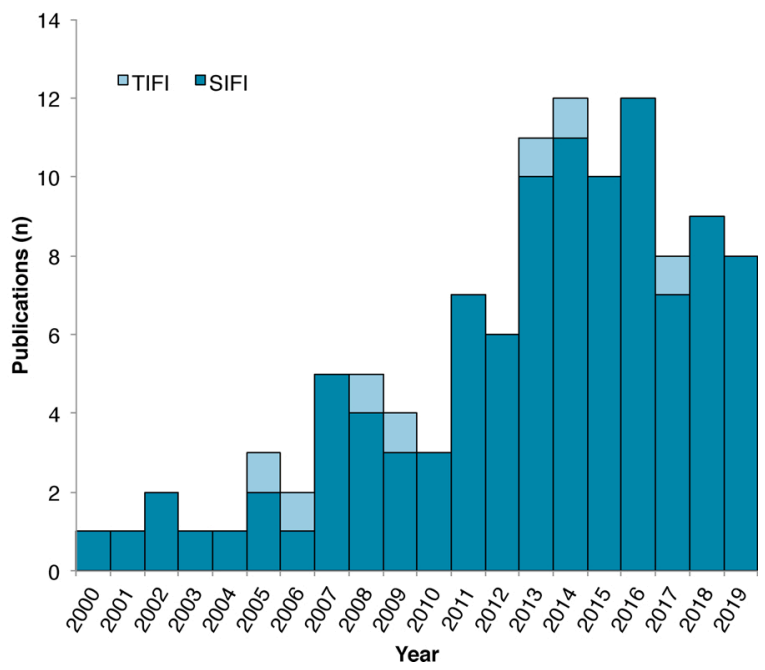

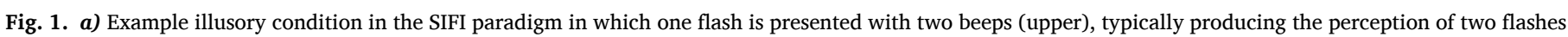

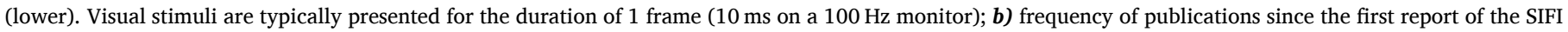
(Shams et al., 2000); TIFI = Touch-Induced Flash Illusion; SIFI = Sound-Induced Flash Illusion. Total $\mathrm{n}=112$. 
visual and auditory stimuli) or if the experimental setup (e.g. task instructions) biases the observer into believing that the flashes and beeps have a common source, an increase the incidence of SIFI would be expected.

To address this latter type of bias, a "coupling prior" was proposed to encapsulate prior expectation of the co-occurrence of sensory signals, in effect serving to determine the probability that two signals originate from the same source and should, therefore, be integrated (Ernst, 2010). While this model can account for behavioural performance better than the maximum likelihood model, due to its linear nature, it still falls short in accounting for situations where sensory signals are segregated, particularly relative to other models such as causal inference (Körding et al., 2007). Substantial evidence suggests that the SIFI reflects Bayesian causal inference in which both the causal structure (i.e. whether or not the flashes and beeps have a common cause) and the integration of the signals (i.e. resolving the discrepancy between the signals if they are inferred to have a common cause) are computed based on normative Bayesian inference (Odegaard et al., 2016; Odegaard and Shams, 2016; Shams et al., 2005b; Wozny et al., 2008). In the causal inference model, all three factors, namely the relative reliability of sensory signals, as well as the prior expectation of numerosity, and the prior expectation of a common cause are taken into account in determining the final percept. Currently, Bayesian causal inference models appear to best describe behavioural performance in the SIFI (Odegaard et al., 2016; Odegaard and Shams, 2016; Shams et al., 2005b; Wozny et al., 2008).

\section{Neural correlates of SIFI susceptibility}

\subsection{Structural and functional correlates}

Most research investigating SIFI suggests that the illusion arises from processes occurring at least as early as primary visual cortical regions (V1) in which auditory inputs influence early visual representations. However, it is also possible that both early and late neural mechanisms contribute to the illusion (Keil, 2020). Candidate cortical regions implicated in the SIFI are illustrated in Fig. 2. Grey matter density in primary visual cortex (V1) has been shown to negatively correlate with SIFI susceptibility in young adults (de Haas et al., 2012). The primary interpretation of this finding is that the weighting of multisensory processing is determined by the availability of neural resources, with less available visual resources (i.e. grey matter) resulting in a greater influence from other sensory systems on perception. An alternative explanation is that the occipital cortex supports multisensory function (Murray et al., 2016b), therefore reduced grey matter in this region corresponds to reduced multisensory integration. Evidence that occipital damage, resulting in visual field defects, reduces SIFI susceptibility supports this idea (Bolognini et al., 2016). Interestingly, de Haas et al. (2012) reported that grey matter density in other candidate regions, such as the Superior Temporal Sulcus (STS), auditory cortex and the superior colliculus (SC), was not associated with SIFI perception.

Using functional magnetic resonance imaging (fMRI), Watkins et al. (2006) found stronger BOLD responses in V1, the right STS and the right SC for trials inducing the SIFI versus no illusion. Watkins et al. suggest that the STS may be the human homologue of the Superior Temporal Polysensory area in macaque cortex previously implicated in multisensory processing (Beauchamp, 2005; Beauchamp et al., 2004; Calvert

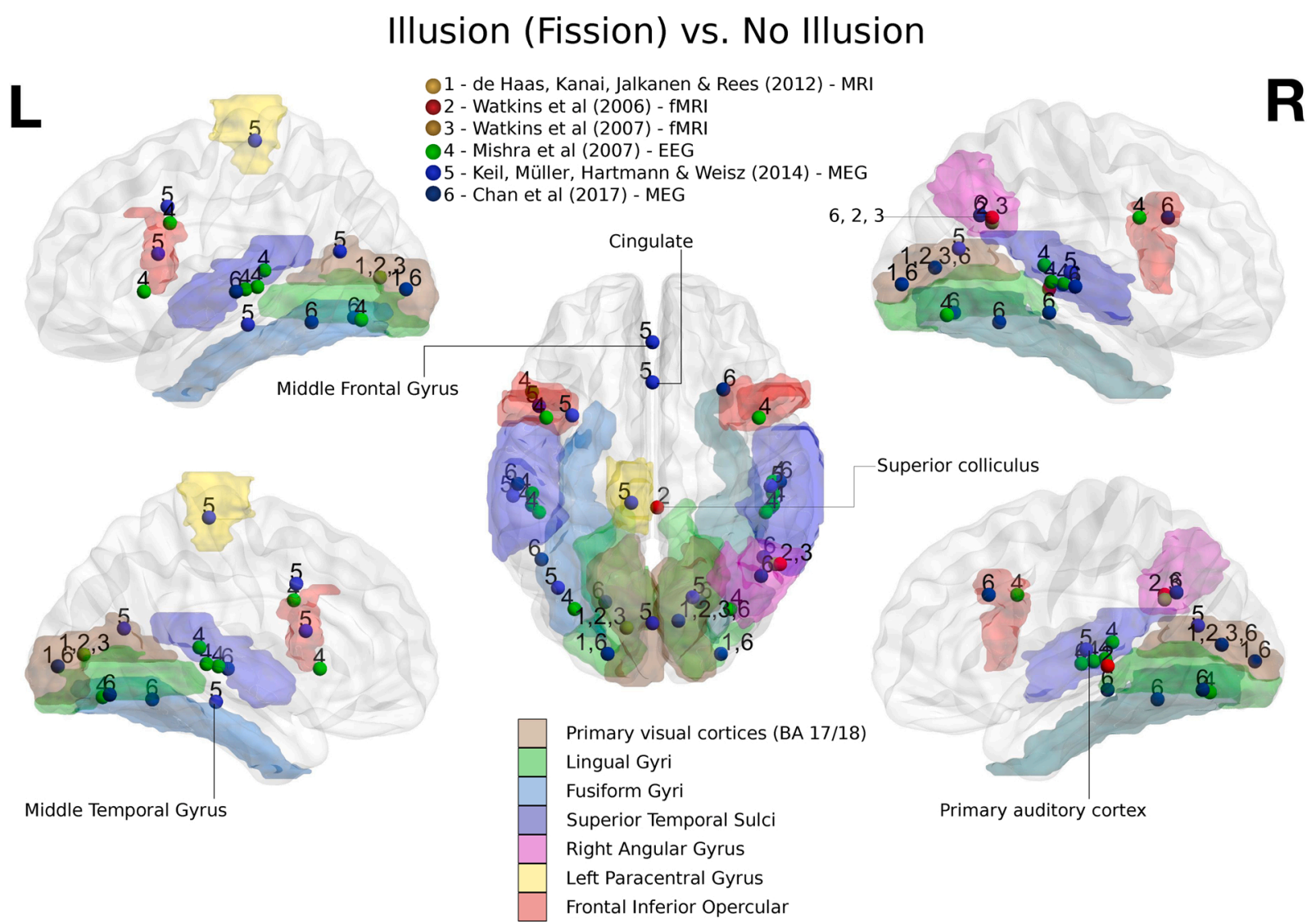

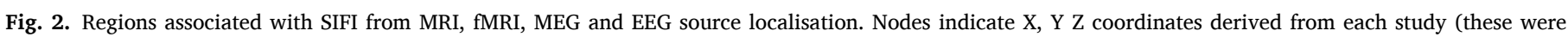

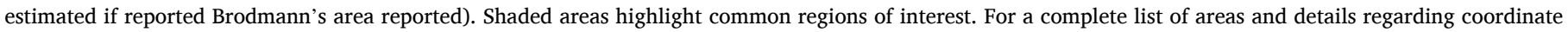
estimation, where applicable, see the Supplementary spreadsheet. 
et al., 2000; Olson et al., 2002). These findings implicate a hierarchy, and possible right lateralisation, of multisensory subcortical and cortical brain regions in producing the SIFI, including the SC, V1 and STS.

\subsection{The time-course of processing}

Given the temporal nature of the SIFI, most investigations as to the neural basis of the illusion have utilised techniques with high temporal resolution (i.e. Electroencephalography, EEG, and Magnetoencephalography, MEG). Modulations associated with SIFI perception have been found as early as $47 \mathrm{~ms}$ post visual stimulus presentation using MEG (Shams et al., 2005a) and $\sim 120 \mathrm{~ms}$ post visual stimulus presentation using EEG (Arden et al., 2003; Mishra et al., 2007). Fig. 3 illustrates the observed timing of these reported effects. The early latency of interactions suggests the illusion originates from direct auditory-visual cortical projections. In support of this, occipital anodal stimulation combined with temporal cathodal stimulation has been found to reduce SIFI susceptibility (Bolognini et al., 2011).

Direct connections between auditory and visual cortical regions, found in non-human primates (Falchier et al., 2002; Rockland and Ojima, 2003) and humans (Eckert et al., 2008), appear predominantly in areas of visual cortex serving peripheral vision, especially regions of the visual field with eccentricities of $10-20^{\circ}$ (Eckert et al., 2008; Falchier et al., 2002). Whilst this might explain why the SIFI, and associated electrophysiological modulations, are more likely to occur to visual stimuli presented in the periphery (Shams et al., 2001), the most common stimulus position is at an eccentricity of $5^{\circ}$, therefore we cannot definitively conclude that direct auditory-visual connections govern the SIFI. Nevertheless, early inter-regional communication may occur via multiple mechanisms, including oscillatory synchronisation and phase resetting (Mercier et al., 2015, 2013).

Mishra et al. (2007) found that an early onset Event-Related Potential (ERP, termed positive deflection, PD120) localised to extrastriate cortices differed between individuals who did and did not perceive the illusion. Two early negative difference components, occurring at $110 \mathrm{~ms}$ and $130 \mathrm{~ms}$ and localised to the superior temporal gyrus, also differentiated trials that evoked or did not evoke the illusion within individuals. The earlier negative deflection (ND) did not significantly differ from the unisensory evoked auditory N1, suggesting that early auditory processing influenced the perception of a secondary illusory flash. The later component, the ND130, was proposed to reflect an electrophysiological manifestation of the associated BOLD response in the STS using fMRI (Watkins et al., 2006). Taken together, this evidence supports a role of both primary sensory (i.e. auditory) and higher order cortical regions in driving SIFI perception.

In further support that crossmodal interactions in the SIFI are not limited to early visual processes. Shams et al. (2005a) reported anterior modulations $\sim 125 \mathrm{~ms}$ post visual stimulus onset, followed by occipital and parietal modulations at $\sim 145 \mathrm{~ms}$, and finally global interactions between $\sim 340$ to $478 \mathrm{~ms}$ post visual stimulus. Keil et al. (2014) also reported cingulate activity $265-280 \mathrm{~ms}$ following auditory stimulus onset specifically associated with illusion trials. Keil et al. attribute cingulate activity to ongoing conflict monitoring processes (Botvinick et al., 2001). Later global activity has been attributed to the generation of a coherent percept established by fusing incongruent audiovisual signals (Bhattacharya et al., 2002; Shams et al., 2005a). Together, these findings indicate that a wide network of cortical regions, recruited at multiple stages of information processing, underlies the SIFI percept.

Studies using Transcranial Magnetic Stimulation (TMS) have shown that the disruption of the right Angular Gyrus (AG) reduces SIFI susceptibility (Hamilton et al., 2013; Kamke et al., 2012). As the AG plays a role in perceiving numerosity (Dehaene et al., 2003), it is possible that these effects reflect altered numerical judgements in the SIFI (Hamilton et al., 2013). Nevertheless, the AG has been described as a crossmodal hub and a convergence zone for sensory and cognitive processes (Seghier, 2013) and recent evidence has linked grey matter volume differences in this region with SIFI perception in older adults (Hirst et al., under review ${ }_{\mathrm{a}}$ ).

Thus far, we have focused on the neural basis of the "fission" variant of the SIFI. However, the literature also points to the existence of a "fusion" illusion, whereby presenting one beep with two flashes results in the perception of one flash (Andersen et al., 2004; Shams et al., 2005b; Watkins et al., 2007; Wozny et al., 2008). It is an open question whether fission and fusion effects reflect the same underlying mechanisms (McGovern et al., 2014). In fusion trials, the response to the second flash is weaker at $\sim 160 \mathrm{~ms}$ post-presentation (Meylan and Murray, 2007). Mishra et al. (2008) found that fusion-related ERP components occurred at $\sim 180 \mathrm{~ms}$ post audiovisual stimulus onset and were localised to superior temporal and inferior frontal gyri. Innes-Brown et al. (2013) found trials associated with the fusion illusion elicited early superior and inferior parietal activity $(130-160 \mathrm{~ms})$ followed by activity in primary and secondary visual cortex (300-320 ms post first stimulus onset). From these studies, the components associated with fusion thus occur later in time relative to fission effects, and modulations seen in V1 may lag those in parietal cortex. However, it is possible that this reflects differences between the visual stimuli across fission and fusion trials (i.e. one versus two events, respectively).

\subsection{Oscillatory activity and pre-stimulus brain states}

Emerging evidence supports oscillatory synchronisation as a core mechanism for inter-sensory interactions (for reviews see Bauer et al., 2020; Keil and Senkowski, 2018). Accordingly, it is thought that the SIFI is also mediated by pre-stimulus brain states and ongoing oscillatory activity in the range of gamma, alpha and beta.

High frequency gamma $(30-90 \mathrm{~Hz})$ oscillatory activity is proposed to arise primarily from perisomatic inhibition (Gyorgy and Xiao-Jing, 2012) and, in harmony with other rhythmic frequency patterns such as beta, is thought to be involved in the anticipatory coordination of multiple brain regions (Engel et al., 2001). Gamma has been associated with numerous cognitive functions including feature binding (Herrmann et al., 2010; Singer and Gray, 1995) and early attention-based modulation in multisensory perception (Senkowski et al., 2005). With regards to the SIFI, pre-stimulus (Kaiser et al., 2019) and post-stimulus (Mishra et al., 2007) gamma-band activity positively correlates with susceptibility (Bhattacharya et al., 2002) and occipital gamma, between $\sim 130$ and $222 \mathrm{~ms}$ post-stimulus onset, has been reported to differentiate trials in which the illusion was perceived or not (Mishra et al., 2007). Gamma activity occurring within this time-frame may reflect top-down attentional effects underlying feature binding (Engel et al., 2001). One mechanism proposed to underlie this phenomenon is inhibitory neural synchronisation mediated by gamma-aminobutyric acid (GABA). Indeed, GABA may provide an index to the ability of neurons to integrate upstream inputs (Gyorgy and Xiao-Jing, 2012). Consistent with this proposal, Balz et al. (2016a) found that GABA concentration in the STS was positively related with both gamma power and SIFI perception. In turn, SIFI susceptibility may therefore provide a biomarker for individual differences in GABA concentration, cortical excitability and the capacity for sensory integration.

Alpha-band activity $(8-12 \mathrm{~Hz})$ typically increases when the eyes are closed and decreases when the eyes are open. Such event-related alpha synchronisation and desynchronisation may reflect cortical inhibition and release from inhibition, respectively (Klimesch, 2012). In the multisensory domain, pre-stimulus alpha has been associated with visual cortex excitability (Lange et al., 2014, 2013), interactions between auditory and visual cortices (Keil et al., 2014) and linking priors with perception (Rohe et al., 2018; see Lange et al., 2014 for a review). In terms of SIFI perception, individuals with lower alpha frequency are more susceptible to the SIFI (Keil and Senkowski, 2017), even in a tactile version of the illusion (van Erp et al., 2014). At an individual level, Keil et al. (2014) found that trials on which the illusion was perceived were associated with increased alpha phase synchrony between auditory and 


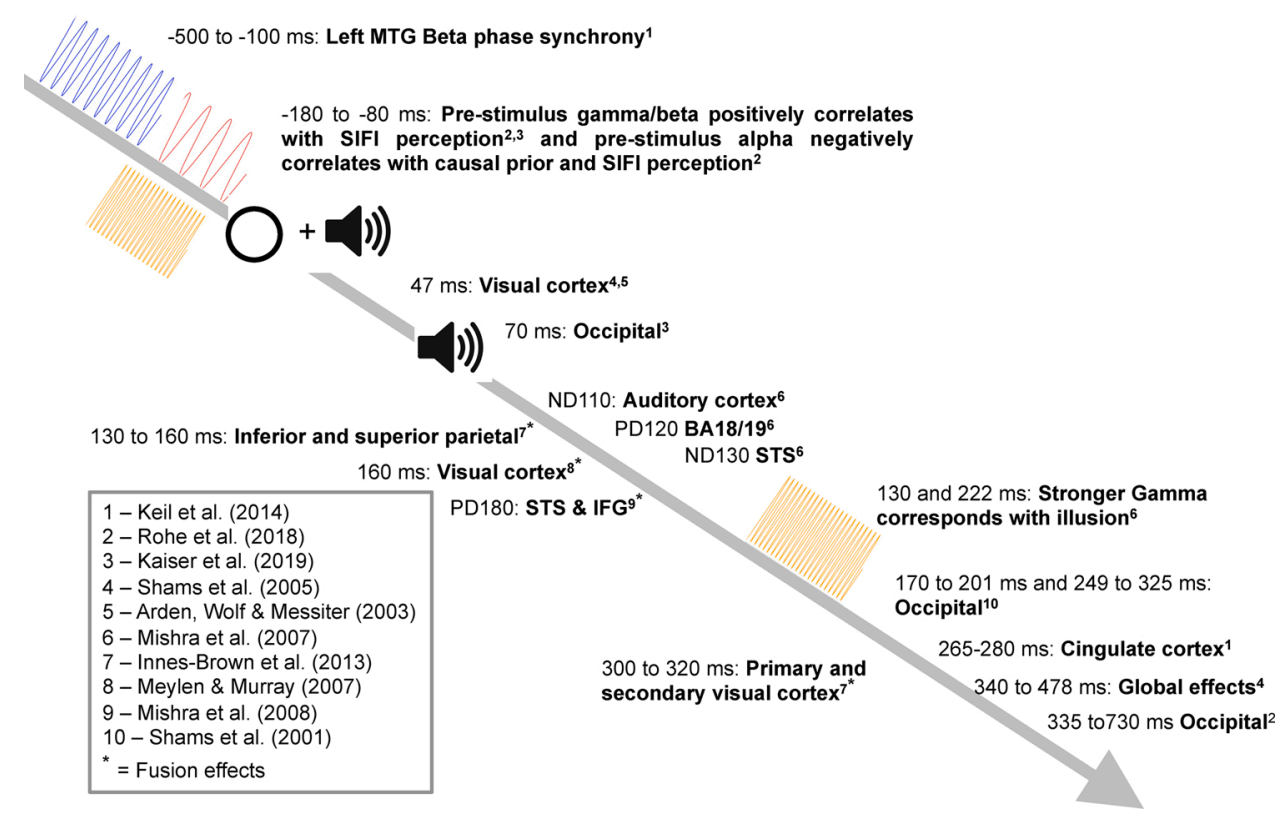

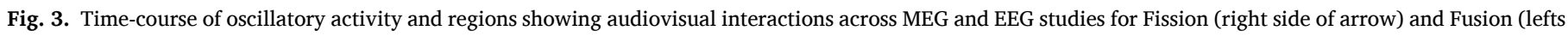
side of arrow) effects. STS = Superior Temporal Sulcus, IFG = Inferior Frontal Gyrus, MTG= Medial Temporal Gyrus.

visual cortices (BA18), as well as between primary visual cortex and medial frontal (BA4) regions, alongside lower synchrony between primary visual and inferior frontal (BA44) regions. Indeed, manipulating occipital alpha frequency towards slower or faster oscillations has been shown to produce stronger and weaker changes in SIFI susceptibility within individuals, respectively (Cecere et al., 2015), while presenting stimuli at the trough of the alpha activity reduces SIFI susceptibility (van Erp et al., 2014). Alpha activity may therefore help elucidate the mechanisms underpinning inter- and intra-individual variability in SIFI susceptibility.

Beta-band activity $(13-35 \mathrm{~Hz})$, associated with spontaneous cognitive processing during rest (Laufs et al., 2003), might indicate individual perceptual predispositions, such as the functional coupling of visual and auditory cortices (Keil et al., 2014), and has therefore been used to infer a network of connectivity underlying SIFI (Chan et al., 2017; Keil et al., 2014). Keil et al. (2014) found that between $\sim 500-100 \mathrm{~ms}$ pre-stimulus onset, stronger beta phase-locking between the Medial Temporal Gyrus (MTG) and auditory cortices and lower phase-locking between MTG and visual cortices preceded the perception of the illusion, suggesting that the MTG might be involved in weighting perception in favour of auditory processing prior to SIFI perception. Additionally, Chan et al. (2017) found that recruitment of the right medial frontal gyrus, as well as connectivity between auditory cortices and the right MTG, related to SIFI perception and that pre-stimulus beta activity was stronger in older adults, possibly indicating a stronger use of priors in this cohort.

Whilst it is useful to consider the role of individual frequency bands, it should be noted that complex cross-frequency interactions also likely underlie the integration processes that give rise to the SIFI (Keil and Senkowski, 2018). For example, beta/gamma activity occurring within 170-50 ms pre-stimulus onset has been shown to predict SIFI perception on a trial-by-trial basis (Kaiser et al., 2019).

\section{Perceptual experience}

Based on the role that prior knowledge plays in multisensory perception (Shams et al., 2005b), it is expected that the SIFI would be influenced by experience. Consistent with this is evidence that the pattern of susceptibility in older adults is influenced by the urbanity of childhood residence (Hirst et al., under review $\mathrm{b}_{\mathrm{b}}$ ). Furthermore, recent exposure to a large number of Stimulus Onset Asynchronys (SOAs) between flash and beep stimuli reduces SIFI susceptibility (Chan et al., 2018). Finally, although trained observers do remain susceptible to the SIFI (Shams et al., 2000), they may obtain a more veridical perception over time, for example, through responding "something other than 1 or 2 flashes" if given this alternative option (van Erp et al., 2013). Understanding whether SIFI susceptibility is modifiable with training or 'expertise' is essential to evaluating whether the SIFI can be used to assess interventions aimed at improving the "efficiency"1 of multisensory integration (e.g. Setti et al., 2014).

\subsection{Perceptual training and the SIFI}

Rosenthal et al. (2009) found that SIFI susceptibility was not influenced by single session, trial-by-trial feedback. However, when feedback was coupled with increasing monetary reward for accuracy, the number of illusory responses reduced although participants still perceived the illusion leading Rosenthal et al. to conclude that the SIFI is a perceptual phenomenon resistant to single session training.

Setti et al. (2014) found that 5 days of training on an audiovisual Temporal Order Judgement task (TOJ) improved the efficiency ${ }^{1}$ of SIFI perception in healthy older adults. However, training effects were not observed in all participants, possibly due to inter-individual differences in susceptibility to training, the initial size of the Temporal Binding Window (TBW) or both (Powers et al., 2009) and it is not yet known whether training effects are sustained over the long term. In contrast to the findings of Setti et al. (2014), Powers et al. (2016) did not find changes to the SIFI following 5 days of training on a simultaneity judgement task; instead they found benefits for discriminating two flashes from one flash when presented in silence or with a congruent number of beeps. However, both studies reported a negative correlation between SIFI susceptibility and the narrowing of the TBW following training. It is possible, therefore, that these training tasks influenced different mechanisms (McGovern et al., 2016a, 2016b) with TOJ training more related to performance on illusory trials. The discrepant

\footnotetext{
${ }^{1}$ Setti et al. use the term "efficient" to refer to a pattern of multisensory integration, typical of young adults (Shams et al., 2000), in which SIFI susceptibility is greatest at SOAs between 70 and $100 \mathrm{~ms}$ but declines at SOAs longer than $100 \mathrm{~ms}$ (e.g. Fig. 4a).
} 
results may also be due to age differences across studies: Powers et al. (2016) recruited younger adults whilst Setti et al. (2014) recruited older adults for whom integration may be less efficient and therefore amenable to improvement.

\subsection{Expertise effects}

To date, two studies have investigated the effect of expertise on SIFI susceptibility, one with musicians and the other with bilinguals. Musicians are reported to have narrower TBWs (Lee and Noppeney, 2014, 2011) and appear less susceptible to the SIFI at long SOAs (Bidelman, 2016) whereas bilinguals appear to have wider TBWs and are therefore more susceptible to the SIFI (Bidelman and Heath, 2018). Musicians represent a group of individuals with expertise in the auditory domain, and manifest more precise temporal judgements for both auditory and visual stimuli (Rammsayer et al., 2012). Consequently, perception in trained musicians appears to be less reliant upon perceptual priors, for example, they appear less influenced by the "central tendency prior" for duration estimation (Aagten-Murphy et al., 2014).

With regards to bilingualism, Bidelman and Heath (2018) highlight that learning a second language requires exposure to, and integration of, unique auditory and visual cues that are often not present in one's first language. However, it remains unclear whether wider TBWs represent an optimal strategy for language learning, as 'over-integration' might be considered suboptimal, resulting in attributing two signals to a common source despite different origins. The implication of audiovisual integration, in the temporal domain, for language learning therefore represents a direction for future research.

\section{Development and ageing}

Multisensory processing is known to change across the lifespan in line with a developmental narrowing of the TBW during childhood followed by age-related widening into older adulthood (Noel et al., 2016). As such, children appear more susceptible to SIFI compared with adults (Innes-Brown et al., 2011) and susceptibility decreases between the ages of 6 and 12 years (Nava and Pavani, 2013). Adams (2016) found that although SIFI susceptibility decreased from 4 to 11 years of age, children younger than 8 years used a modality switching strategy. Thus, SIFI susceptibility in early childhood might not arise from the same optimal integration processes reported in adults (Odegaard and Shams, 2016; Shams et al., 2005b; Wozny et al., 2008).

A developmental decrease in SIFI susceptibility is consistent with a protracted development of multisensory integration (Ernst, 2008; Gori et al., 2008; Murray et al., 2016a) and a developmental shift in sensory dominance, from audition towards vision with development (Hirst et al., 2018a; Nava and Pavani, 2013). However, not all studies report a developmental decrease in SIFI susceptibility. For example, Tremblay et al. (2007) reported an increase in the McGurk effect, a speech perception illusion, between the ages of 5 and 19, but no evidence for a change in SIFI with age. One potential explanation for this result is that, if children are more auditory dominant (Hirst et al., 2018a) and audition is still likely to influence visual perception in early childhood, then young children would be susceptible to illusions in which audition influences vision (i.e. SIFI) but not vice versa (i.e. McGurk) (Hirst et al., 2018b; Nava and Pavani, 2013). Moreover, the distribution of ages differs across studies (6-12 year olds in Nava and Pavani, 2013; $5-19$ year olds in Tremblay et al., 2007) and it is possible that greater changes in SIFI perception are observed in early childhood.

Older adults are generally more susceptible to the SIFI than younger adults and remain susceptible to the illusion at longer SOAs (McGovern et al., 2014; Setti et al., 2014, 2011). This increase in susceptibility with ageing is supported by evidence from a large population based study, The Irish Longitudinal Study on Ageing (TILDA), in which over 4000 individuals aged over 50 were tested. The first analysis of this dataset showed that key predictors of SIFI susceptibility were participant age, sex and cognitive status (Hernández et al., 2019; Hirst et al., 2019b). Follow up work in the TILDA study has shown that age-related changes are in part, but not fully, accounted by age-related changes in unisensory function (Hirst et al., 2019b; Hirst et al., 2020).

Perceptual experience across the lifespan might also alter susceptibility to the SIFI as the role of relevant priors might increase (e.g. Chan et al., 2017). Accordingly, when stimuli are presented over large SOAs in the SIFI, older adults might continue to use auditory information based on prior knowledge and altered unisensory sensitivity, despite the larger temporal discrepancy between the signals.

Fission and fusion effects have been shown to follow different trajectories across development and particularly with ageing. Innes-Brown et al. (2011) found that although fission illusions decreased with development, child and adult groups performed similarly for fusion illusions. Similarly, McGovern et al. (2014) found that whilst older adults were more susceptible to fission illusions, the fusion illusion did not significantly differ between younger and older adults. This finding suggests that dissociable neural mechanisms may underpin fission and fusion illusions (discussed in more detail in Section 7).

One possibility is that the processes giving rise to fusion effects are less susceptible to age-related decline. For example, attentional manipulations of the SIFI (i.e. using a go no-go task in one modality) appear to have a similar effect in younger and older adults (DeLoss et al., 2013). However, a more parsimonious account for differences in fission and fusion effects across the lifespan may be related to unisensory discriminability. For example, Hirst et al. (2019b) reported that accuracy for discriminating two flashes improved with age, whilst accuracy for detecting two beeps declined with age. Since susceptibility to fission illusions is influenced by the ability to detect two beeps, greater accuracy would correspond to a stronger illusory percept (as such, older adults are less susceptible to fission effects at very short SOAs, Fig. 4b). In contrast, fusion illusions result from pairing two flashes with one beep, therefore a more reliable discrimination of two flashes would mean that illusion susceptibility would not increase with age for fusion effects. This emphasises the importance of taking individual unisensory perceptual ability (i.e. discriminating two visual or two auditory stimuli) into account during analysis of the results, or by adapting the timing of stimuli presented during the task to the level of threshold performance.

In an examination of the SIFI in both development and ageing, Parker and Robinson (2018) investigated the effect of vision upon audition and vice versa. When asked to judge the number of flashes, fission effects reached significance in younger and older adults but not in children (contrasting Innes-Brown et al. (2011) and Nava and Pavani (2013)). In line with McGovern et al. (2014), older adults did not significantly differ from young adults in fusion susceptibility. When asked to judge the number of beeps, children and older adults showed a stronger influence of vision on audition compared with younger adults, and this was the case for both fission and fusion illusions (in this case, reverse SIFI effects, as the number of visual stimuli altered the number of perceived auditory events). This latter effect suggests that children and older adults might show differences in how they weight sensory signals relative to young adults. An open question is to what extent these differences are attributable to relative temporal precision across vision and audition and how this may change across the lifespan.

\section{Individual differences and clinical groups}

As discussed, the SIFI provides insight into the efficiency of multisensory integration processes through gauging optimal integration as well as the width of the TBW. Following this, many studies have implemented the SIFI to characterise individual differences in multisensory integration and perceptual differences in neurotypical and clinical subgroups. The broad range of clinical fields in which the SIFI has been applied illustrates its versatility as a promising research tool to gain insight regarding the capacity for sensory integration.

Prior to a more detailed discussion, it is worth noting that several 


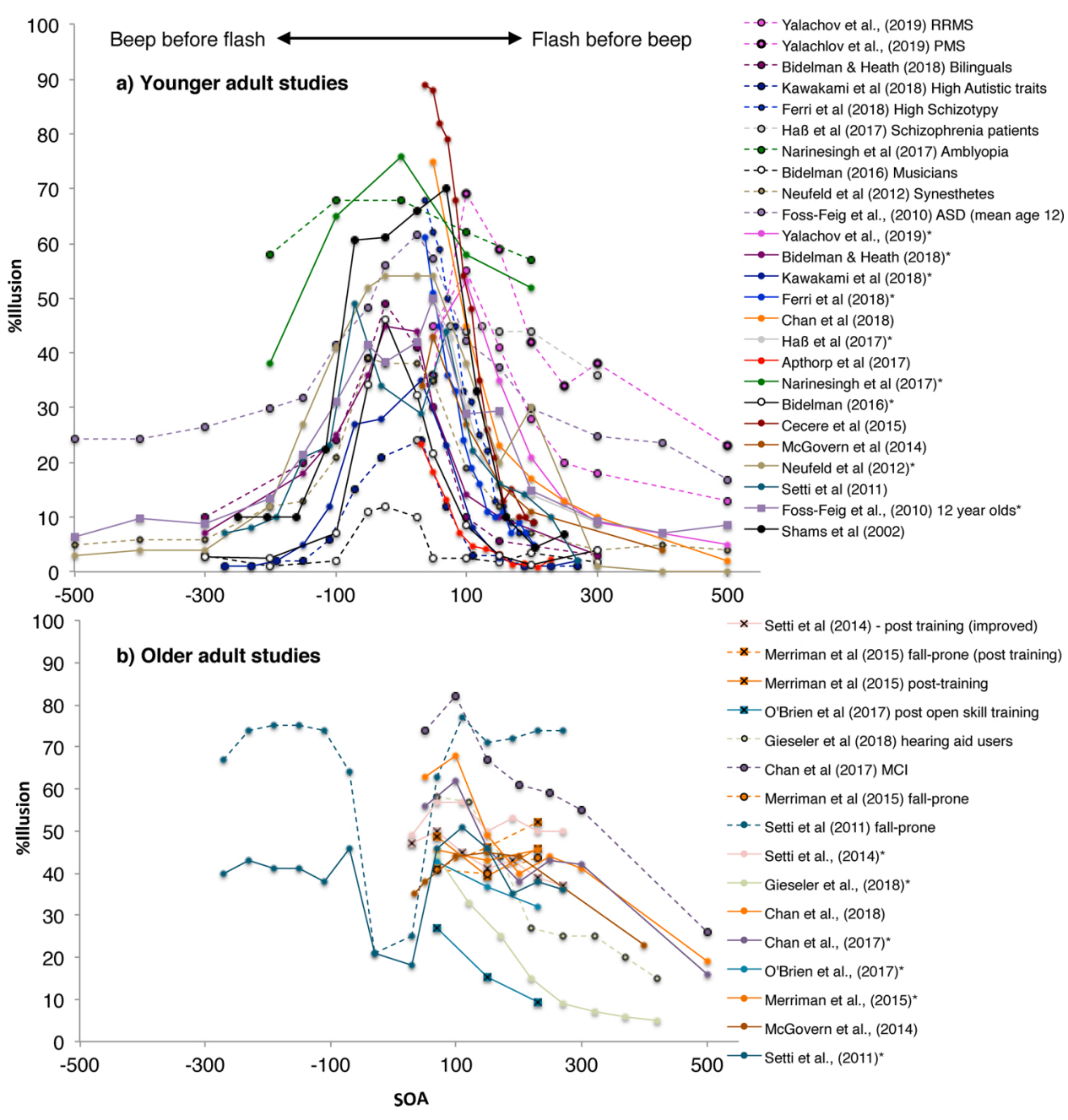

Fig. 4. Studies using Stimulus-Onset Asynchrony (SOA) in ms used to assess SIFI susceptibility and the width of the Temporal Binding Window in younger (a) and older (b) adults. Colours correspond to each study. Dashed lines $=$ groups of interest (i.e. not controls). Continuous lines = healthy/control groups. Crosses indicate post-training effects. Asterisks in the legend indicate this group has a comparison group of interest in the same plot. RRMS $=$ Relapse Remitting Multiple Sclerosis; PMS $=$ Progressing Multiple Sclerocis; MCI = Mild Cognitive Impairment. clinical areas show inconsistent SIFI effects across studies. These areas include Autism Spectrum Disorder (ASD), schizophrenia and migraine. Studies of syneasthesia, although non-clinical, are also associated with inconsistent findings. There are several possible reasons for this, with some more obvious suggestions. First, these conditions are often associated with heterogeneous symptom profiles or phenotypes, which likely have corresponding heterogeneities in terms of SIFI perception. Second, different methodologies have been used with potential effects on perceptual learning and updating of priors. Third, differences in unisensory ability are often not consistently controlled for across participants. These aspects represent important considerations and opportunities for future work.

\subsection{Visual and hearing ability}

In line with probabilistic inference models of multisensory integration in which sensory signals are weighted by their reliability (Ernst and Bülthoff, 2004; Körding et al., 2007; Shams et al., 2005b; Wozny et al., 2008), visual and hearing impairments have been shown to result in stronger and weaker SIFI susceptibility, respectively, as occurs, for example in age-related sensory changes (Hirst et al., 2019b; Hirst et al., 2020).

Studies with young adults have yielded differing effects of sensory impairment on SIFI depending on the nature of the condition. For example, Narinesingh et al. (2017) found that individuals with amblyopia remained susceptible to the fission illusion at long SOAs (but had fewer fusion illusions compared with controls when viewing with the amblyobic eye). However, it is unknown whether this finding resulted from sensory ability at the time of testing or atypical visual experience during critical developmental periods which subsequently shapes multisensory integration in later life (Chen et al., 2017b).

In contrast to the effects observed in amblyopic patients, Moro and Steeves (2018) found that individuals who lost an eye in early life (monocular enucleation) were not susceptible to fission illusions, despite having normal TBWs. Furthermore, they found no evidence for a correlation between TBW width and SIFI susceptibility in these individuals, in contrast to findings from a neurotypical population based on similar stimuli and task (Stevenson et al., 2012). Although audition might be expected to have greater influence over vision in cases of monocular enucleation, atypical patterns of multisensory perception have been reported within this group, including no visual dominance when tested with the Colavita task (Moro and Steeves, 2013, 2012) and altered white matter structure in the visual cortex (Wong et al., 2018). Instead, Moro and Steeves (2012, 2013) suggest equal visual and auditory weighting in general in individuals with one eye, which might render this group less susceptible to the SIFI.

With regards to auditory abilities, Gieseler et al. (2018) found that hearing aid users showed wider TBWs and increased SIFI susceptibility compared with age-matched controls (with the same degree of hearing loss). Importantly, the intensity of the auditory stimulus was adjusted based on individual subjective audibility rating, thus, between-group differences were not due to differences in overt stimulus detectability. These findings are consistent with previous studies reporting similar effects of self-reported hearing in ageing (Hirst et al., 2019b; although see Hirst et al., 2020) as well as increased functional connectivity between visual and auditory cortices in age-related hearing loss 
(Puschmann and Thiel, 2017).

\subsection{Cognitive function}

Strong evidence has emerged to support the idea that multisensory integration is associated with cognitive function (see Wallace et al. (2020) for review). As discussed in relation to ageing, prolonged susceptibility to the SIFI over long SOAs is associated with poor general cognitive performance (Montreal Cognitive Assessment scores) (Hernández et al., 2019), and specifically, executive function and memory (Hirst et al., in prep). Several other lines of evidence support SIFI as a marker of cognitive function in ageing and clinical subgroups. For example older adults with mild cognitive impairment (MCI) remain susceptible to the SIFI at longer SOAs (Chan et al., 2015), increasing cognitive load in young adults increases SIFI susceptibility (Michail and Keil, 2018) and SIFI susceptibility correlates with cognitive impairment and memory capacity in patients with Multiple Sclerosis (Yalachkov et al., 2019).

Other factors influencing cognitive function across the life-course, particularly exercise, have also been linked to individual differences in SIFI susceptibility. For example, O'Brien et al. (2017) found that one bout of open skill (i.e. tennis or dancing) but not closed-skill (i.e. swimming) exercise in adults improved the detection of two veridical compared with two illusory flashes. Similar findings were reported in a follow-up study, where exercise benefited multisensory perception and working memory (digit span) in children (O'Brien et al., 2020). However, evidence for a direct link between working memory and SIFI was not reported in this developmental population. It is possible that their findings reflect an impact of short-term arousal on visual temporal perception (e.g. Lambourne et al., 2010), independently of multisensory function. Nevertheless, evidence from younger (Michail and Keil, 2018) and older adults (Hirst et al., in prep) does support a relationship between working memory and SIFI perception.

\subsection{Fall-prone older adults}

Balance and postural control are, inherently, multisensory functions (Bronstein, 2016) relying on both vision and hearing as well as other sensory systems such as proprioception and vestibular processing (Campos et al., 2018; Gerson et al., 1989). As such, impaired multisensory integration may predispose older adults to a risk of falling (Zhang et al., 2020). Consistent with this, fall-prone older adults remain susceptible to the SIFI illusion at longer SOAs compared with age-matched non-fallers (Setti et al., 2011) (Fig. 4b), particularly when tested in a standing position (Stapleton et al., 2014). Interestingly, older adults who are slower walkers are also more susceptible to SIFI at longer SOAs compared with faster walkers (Settiet al., in prep.), and gait speed is a known risk-factor for falls (Kyrdalen et al., 2019; Prince et al., 1997; Tay et al., 2015). These findings suggest that the SIFI could help assess fall risk as well as the effectiveness of interventions such as chiropractic care (Holt et al., 2016) and balance training (Merriman et al., 2015) which have both been shown to shape SIFI susceptibility. An open question is what mechanism mediates between SIFI susceptibility and postural control: it is possible that both tasks require coordination of multiple sensory systems (e.g. sensory reweighting) in the temporal domain although other processes, such as temporal precision, may also play a role.

\subsection{Autism Spectrum Disorder}

Atypical sensory processing is recognised as a core characteristic of ASD (for review see Marco et al., 2011). However, findings regarding SIFI susceptibility in ASD have been mixed. Children with ASD have been shown to be more (Foss-Feig et al., 2010) and less (Stevenson et al., 2014) susceptible to the SIFI compared with age- and IQ-matched peers. Susceptibility in adults with ASD appears similar to that of age-matched controls (Keane et al., 2010; van Der Smagt et al., 2007), whereas in the general population, subclinical traits of ASD, specifically in the domains of social skill, communication and imagination, have been associated with weaker SIFI susceptibility (Kawakami et al., 2018).

ASD has been associated with a broad spectrum of clinical profiles and it is possible that mixed reports of SIFI effects might reflect this. Alternatively, the mixed results may reflect individual differences in unisensory function. Although Foss-Feig et al. (2010) did not find significant group differences in the ability to detect two flashes, participants accuracy for detecting the number of beeps was not assessed. Therefore, it is not possible to tell if there was similar auditory accuracy in the ASD groups across studies.

An alternative explanation for the discrepant results across studies involving children with ASD may be differences in methodology, in particular the number of SOAs used. By manipulating SOA, Foss-Feig et al. (2010) found that children with ASD had wider TBWs. Conversely, Stevenson et al. (2014) did not manipulate SOA, but found that children with ASD were less likely to perceive the SIFI. One possibility is that children with ASD may not update their perceptual priors following exposure to a range of SOAs (see Chan et al., 2018), thereby leading to relatively stronger SIFI susceptibility specifically at longer SOAs. Indeed, according to predictive coding models of multisensory integration in ASD (Chan et al., 2016), and the High, Inflexible Precision of Prediction Errors Account (HIPPEA) (Van de Cruys et al., 2014), individuals with ASD give more weighting to prediction errors and become less reliant upon priors. As such, individuals with ASD might be less likely to show a benefit from experience on SIFI susceptibility.

Similar SIFI perception has been reported between adults diagnosed with ASD and controls (Keane et al., 2010; van Der Smagt et al., 2007), although this may be specific to fission than fusion effects (Bao et al., 2017). It has been suggested that individuals diagnosed with ASD undergo a developmental delay in sensory processing, with multisensory abilities reaching age-normal levels by mid-twenties (Crosse et al., 2019). Findings from studies using the SIFI therefore support this conclusion. However, to our knowledge, SIFI susceptibility in children and adults with ASD have yet to be compared within the same study.

\subsection{Schizophrenia}

Altered multisensory integration is a commonly reported characteristic of schizophrenia (Postmes et al., 2014). However, as with other conditions that present heterogeneous phenotypes, the data regarding SIFI susceptibility in schizophrenia remains mixed, with reports of reduced (Vanes et al., 2016), similar (Balz et al., 2016b) and stronger (Ferri et al., 2018; Haß et al., 2017) susceptibility. In particular, the tendency to bind information appears negatively associated with prodromal traits (Odegaard and Shams, 2017). This does not appear related to unisensory visual function, particularly visual gap detection, which did not differ across groups (Vanes et al., 2016). However, it remains possible that differences in auditory gap detection might exist and, as such we cannot conclude that mixed results cannot be attributed to such differences.

Similar to studies of ASD, methodological differences relating to the manipulation of SOAs also exist in the literature investigating schizophrenia. Studies manipulating SOA have found stronger SIFI susceptibility at long SOAs in individuals with schizophrenia (Haß et al., 2017) or high schizotypal traits (Ferri et al., 2018) (see Fig. 4), whilst studies that have not manipulated SOA report no group differences in behaviour (Balz et al., 2016b). As we argued in the previous section on ASD (Section 5.4), differences in the updating of perceptual priors based on experience could explain some of the discrepancies observed across studies. Indeed, beta-band activity, a phenomenon associated with the use of priors (see Section 2.3), has been shown to differ between individuals with schizophrenia and controls on trials that did or did not induce the SIFI (Balz et al., 2016b), despite no evidence for group differences in illusion susceptibility. Although a discussion of the ability to 
implement and adjust priors in schizophrenia is beyond the scope of this review (but see Sterzer et al., 2018), recent evidence suggests that individuals with schizophrenia are able, albeit slower, to acquire priors compared with controls (Valton et al., 2018). A direction for future research is therefore to assess whether wider TBWs in schizophrenia, measured via the SIFI, reflect inefficient integration, or impaired updating of priors.

Given that GABA levels in the STS positively correlate with SIFI perception in healthy individuals (Balz et al., 2016a), and considering that GABA mediates multisensory perception in rodent models of schizophrenia (Cloke et al., 2016), it is reasonable to assume that aberrant GABAergic function mediates group differences in the SIFI. However, Balz (2018, Chapter 5) reported that GABA concentration in the STS did not predict illusion perception in patients with schizophrenia although, curiously, such a correlation was observed in a control sample (Balz et al., 2016a). These findings suggest that factors other than GABA concentration, such as differences in the use of priors, may explain these group effects.

\subsection{Synaesthesia}

Synaesthesia is a neurological condition characterised by sensory experience in one or more modalities elicited by a veridical stimulus presented to another sensory modality or sub-modality (Baron-Cohen et al., 1996; Newell and Mitchell, 2016; Simner et al., 2006). Studies investigating multisensory function in synaesthesia often use measures of SIFI susceptibility but to mixed results, with reports of enhanced (Brang et al., 2012), reduced (Neufeld et al., 2012) or normal (Whittingham et al., 2014) SIFI perception. Again, however, differences in methodologies across studies as well as the heterogeneity of the condition make direct comparisons difficult. For example, Brang, Williams, and Ramachandran (2012) studied individuals with grapheme-colour synesthesia using a single SOA, whereas Whittingham, McDonald, and Clifford (2014) and Neufeld et al. (2012) both tested a wide array of SOAs. In synaesthesia, it is likely that differing SIFI effects may reflect differing neurocognitive profiles involving unique subsets of sensory modalities and their interactions, as well as differences in sensitivity to the presentation of sensory stimuli.

\subsection{Migraine and headaches}

Migraine is a common neurological disorder characterised by a unilateral, pulsating headache with moderate to severe pain. Migraines are accompanied by changes in sensory processing, including heightened sensitivity to light (photophobia) and sound (phonophobia), and altered multisensory processing (for reviews see, O'Hare, 2017, and Schwedt, 2013).

Several studies have investigated the association between migraine and multisensory perception using the SIFI. Adults with migraine (Brighina et al., 2015, 2014) and cluster headaches (Cosentino et al., 2015) appear less susceptible to the SIFI although susceptibility in children with migraine does not differ from their age-matched peers (Di Marco et al., 2015). Lower susceptibility in adults suffering migraine is an unexpected finding given that migraine is associated with a wider TBW (Yang et al., 2014). Weaker SIFI perception in migraine has been attributed to visual cortex hyperexcitability (Cosentino et al., 2015) resulting in vision being less susceptible to the influence of audition. In accordance, menstrual migraine does not show the same cycle-dependant pattern of SIFI susceptibility as controls for whom susceptibility fluctuated with the phase of the menstrual cycle (progesterone is thought to reduce cortical excitability by binding to GABA receptors) (Maccora et al., 2015). Despite the idea that cortical excitability may link migraine and SIFI, occipital cathodal stimulation has been reported to have no effect on SIFI perception in this group (Maccora et al., 2019 although see Brighina et al., 2014). Although findings are currently mixed, studies examining migraine have started to provide interesting insights into the role that cortical excitability might play in SIFI perception.

\section{The SIFI paradigm: stimulus parameters and guidance for future research}

If the SIFI is to be implemented as a clinical tool and recommended for use in large-scale data collection it is essential to understand the role of stimulus parameters on the SIFI in order to select an optimal protocol and strive for harmonisation across research.

Much has been learned about the SIFI and its potential neural mechanisms through the manipulation of the audiovisual stimuli used to generate the illusion. To facilitate future research, we have compiled a Supplementary table ${ }^{2}$ detailing the most commonly reported stimulus parameters used to elicit the SIFI and open-source examples of the SIFI task have recently been provided (Keil, 2020). Across studies, the most commonly used parameters include a $2^{\circ}$ white disk presented $5^{\circ}$ below fixation for $10 \mathrm{~ms}$, accompanied by two $80 \mathrm{~dB}, 3500 \mathrm{~Hz}$ tones presented for $10 \mathrm{~ms}$ each. The first tone is usually presented at the same time as the visual stimulus, or $\sim 23 \mathrm{~ms}$ prior to the visual stimulus (Shams et al., 2002). As shown in Fig. 4 the SOA between the first and the second tone systematically alters the strength of the illusion, therefore the selection of these parameters has important consequences for performance. It has recently been shown that performing the SIFI task with a confederate present can enhance the illusion (Wahn et al., 2020): the confederate was asked to judge the number of beeps, whilst the participant judged the number of flashes. The authors attribute enhanced illusion susceptibility to the presence of a visual distractor (another person). Researchers might therefore want to consider if the experimenter or other individuals are in view at the time of SIFI assessment.

Shams et al. (2000) reported that the SIFI was robust to changes in stimulus features, including changes in contrast, shape, texture, stimulus duration, and spatial disparity between the auditory and visual stimuli. As such, although most studies have presented a peripheral, high contrast disk, the SIFI has been observed with a range of stimuli, including Gaussian blobs (Apthorp et al., 2013), checkerboards (Arden et al., 2003) annuli surrounding the point of fixation (McGovern et al., 2014; Stevenson et al., 2012), and phosphenes induced by TMS (Bolognini et al., 2013).

The SIFI has also been found, albeit with a reduced potency, using complex stimuli such as block patterns (Takeshima and Gyoba, 2013), familiar faces and buildings (Setti and Chan, 2011). Relatively less focus has been given to the effect of auditory stimulus complexity in the SIFI, therefore a consensus on this parameter has yet to be reached. For example, presenting two beeps at different frequencies has been shown to both enhance (Wilkie et al., 2008) and abolish (Roseboom et al., 2013) the illusion. Nevertheless, the current findings indicate that, in most cases, the SIFI persists despite changes in stimulus complexity and is therefore not bound to the simple flash and beep stimuli most commonly reported in the literature.

The SIFI appears robust to spatial discrepancy between visual and auditory stimuli. SIFI effects have been observed with cross-modal separations as large as $20^{\circ}$ (Innes-Brown and Crewther, 2009) and $50^{\circ}$ (Deloss and Andersen, 2015). Based on research on the multisensory properties of neurones within the SC of the cat (Meredith and Stein, 1996), spatial coincidence has been discussed as a rule, or principle, of multisensory integration (Stein et al., 1989). However, receptive fields of the SC are relatively large and overlapping (Kadunce et al., 2001) and several behavioural studies have reported that bimodal stimuli do not need to be presented in identical locations to elicit integration (Spence, 2013, 2019). Thus, the SIFI may not be constrained by precise

\footnotetext{
${ }^{2}$ This table is available at https://osf.io/w46zy/. We encourage researchers implementing the SIFI to continue to contribute to this table so that we may continue to accurately document SIFI research.
} 
coincidence in the spatial domain. One study did find that presenting beeps to the same versus opposite hemifield as the visual stimuli produced stronger susceptibility to the SIFI (Bizley et al., 2012). However, in that study, the stimuli presented to each hemifield also differed in colour and timbre, potentially limiting perceptual grouping of unisensory signals and encouraging crossmodal competition (Kumpik et al., 2014).

\subsection{Detectability of the auditory and visual stimulus}

Despite the robustness of the SIFI, stimulus detectability can influence the probability that a participant will experience the effect. Although this has implications for participants with a sensory impairment (Section 5.1), it is equally important to understand the effects of specific stimulus parameters in healthy participants. It is known that reducing the intensity of the auditory stimulus weakens SIFI susceptibility (Andersen et al., 2004; Cuppini et al., 2014) and the effect appears strongest when small, peripheral, visual stimuli are used. Shams et al. (2001) found that, on average, participants reported illusory effects on $81 \%$ of trials when stimuli were presented in the periphery versus $21 \%$ if visual stimuli were presented centrally. This peripheral versus foveal difference might be due to the lower reliability of the visual stimulus with increasing eccentricity and/or possibly more extensive projections from auditory cortex and multisensory cortical areas (such as STS) in the peripheral representations compared to foveal representations of the visual context (Clavagnier et al., 2004; Falchier et al., 2002). Furthermore, it is possible that the stimuli presented in the SIFI are processed at early stages of visual processing by the magnocellular pathway (Pérez-Bellido et al., 2015), which is sensitive to transient stimuli (Maunsell et al., 1999) and more strongly represented in the periphery (Malpeli et al., 1996).

Increasing luminance contrast has been reported to enhance SIFI susceptibility (Pérez-Bellido et al., 2015). Pérez-Bellido et al. suggest that, because illusory flash perception arises from early visual cortex, the low-level stimulus properties that modulate perception of the actual flash also modulate perception of the illusion (i.e. if the actual flash is more intense, the illusory flash will also be more intense). In line with this, when the actual flash is white, the illusory flash also appears white (McCormick and Mamassian, 2008). However, another possibile reason for the effects reported by Pérez-Bellido et al. is that differences could be due to the physical and practical limitations of presenting stimuli onscreen. Specifically, because increasing luminance also increases the decay period of the phosphor, it is possible that the SOA between the flash and the second beep, and also between two flashes in the two-flash condition, is reduced. Consequently, it is possible that presenting stimuli with higher luminance increases the difficulty of the task (through reducing SOA) and increases SIFI effects. It is possible that some of these questions may be addressed by comparing SIFI effects when stimuli are presented onscreen versus via an LED.

\subsection{Stimulus-onset asynchrony (SOA)}

In line with the temporal nature of the SIFI, arguably the most critical parameter known to modulate the SIFI is the SOA between the first flashbeep pair and the second beep. Shams et al. $(2000,2002)$ found that SOAs over $70 \mathrm{~ms}$ reduced the illusion with virtually no illusions at longer SOAs such as $200 \mathrm{~ms}$. This reduced susceptibility to the SIFI with SOAs over $70 \mathrm{~ms}$ in young adults is consistent with the reported temporal binding properties of polysensory neurones at least in the SC (Meredith et al., 1987; Wallace and Stein, 1994). Indeed, temporal co-incidence has been proposed as a principle of multisensory integration (Stein and Meredith, 1993). As such, the time window of SIFI susceptibility has become a popular tool to map healthy and clinically relevant changes in multisensory function. A summary of findings from studies manipulating SOA in the SIFI is shown in Fig. 4. In line with our discussion of the use of SIFI in clinical contexts and the effect of Bayesian priors on perception (Sections 5.4 and 5.5), a careful consideration of the number and range of SOAs is merited when assessing the temporal limits of multisensory perception using the SIFI.

\subsection{Adapting stimuli to individual sensory function}

Based on evidence that stimulus intensity and sensory ability systematically alter SIFI susceptibility, future research may wish to consider adjusting stimulus properties for each participant according to their sensory abilities (where possible within the practical restrictions of the design). For example, previous approaches in multisensory research include presenting stimuli a set level above auditory and visual threshold (Hirst et al., 2019a), or a set level above subjective audibility rating (Gieseler et al., 2018). The same considerations should be made for selecting the SOA, by taking into account an individual's ability to discriminate two unimodal stimuli at any particular SOA. For example, if two beeps cannot be discriminated, then a "two flash" response would be unlikely on illusory trials. This is particularly relevant to clinical work and studies examining lifespan effects, in which different groups of participants may exhibit different unisensory temporal resolutions, perhaps accounting for the dip in illusion susceptibility at short SOAs in older adults, (Fig. 4b). In these cases, the timing of sequential stimuli should be selected to avoid confounding effects. For example, Adams (2016) used stimuli with a gap of $\sim 117 \mathrm{~ms}$ in adults, whilst a gap of $\sim 200 \mathrm{~ms}$ was required in young children to achieve equivalent perceptual performance. Following a selection of appropriate SOAs, the inclusion of unisensory trials will also allow the experimenter to identify baseline sensory ability and control for such differences in the analyses.

\section{Discussion}

In this review, we synthesise twenty years worth of research based on the Sound-Induced Flash Illusion (SIFI). In this time, remarkable progress has been made in understanding the mechanisms that give rise to the SIFI, which in turn has informed our understanding of how the human brain combines information across the senses (Keil, 2020). In recent years this acquired knowledge from the SIFI has been used to good effect to assess the integrity of sensory processing in a variety of clinical populations. More generally, the ability to integrate information across the senses has recently emerged as a potential tool for understanding healthy and pathological cognitive function (Wallace et al., 2020). It is therefore more crucial than ever to synthesise what we know about existing measures of multisensory function so that, in the next few years, multisensory integration might be considered a complimentary clinical tool to accompany unisensory measures. A critical step towards this is to establish optimal and standardized stimulus parameters, identify relevant neurological mechanisms and understand what is known with regards to healthy and clinically relevant differences in task performance.

We began by highlighting the importance of the SIFI in propelling a paradigm shift towards a more general account of multisensory processing. We then reviewed the neural correlates of SIFI perception. Convergent findings show that the neural origin of the SIFI most likely lies in early visual processing, in which inputs from other sensory modalities (i.e. audition) directly modulate activity in V1 or earlier. Furthermore, the behavioural effects might be governed through direct connectivity between sensory cortices (Eckert et al., 2008; Falchier et al., 2002; Rockland and Ojima, 2003), in particular structural projections connecting auditory cortex with regions of visual cortex serving peripheral vision (Eckert et al., 2008). An important issue for future research to address is to systematically alter the eccentricity of the visual stimulus, to determine whether the SIFI is optimal when presented to those regions of the visual field that specifically receive direct projections from auditory cortex.

A recurrent theme across studies is that the fusion illusion (reporting one flash when two flashes are presented with one beep) has been far 
less studied in comparison with fission effects (reporting two flashes when one flash is presented with two beeps). One possible reason for this is that fission effects can be considered, intuitively, more exciting, because they create the perception of a second visual stimulus that did not physically occur. A second possible reason is that fusion effects are less reliable compared with fission effects. As such, many studies do not investigate fusion illusions and, subsequently, much less is known about their origin.

Of the studies that have investigated fission and fusion, several converging patterns have emerged (Table 1). The observed differences in fission and fusion to date imply that the SIFI may provide multiple outcome measures of multisensory processing. However, it must be considered that fission and fusion effects could be differentially influenced by similar parameters. For example, the reliability of the representation of one flash and two flashes might differ, and this difference may vary across age, populations, and stimulus conditions. The prior expectation of numerosity can also vary across individuals and populations, and thus influence the relationship between fission and fusion differently. An individual with a prior bias for a larger numerosity would exhibit a stronger fission illusion and a weaker fusion illusion. Therefore, fission and fusion effects might reflect the same mechanisms that are differentially affected by individual differences in temporal precision and/or prior expectation.

For future research designed to understand the differences between fission and fusion effects, it would be wise to implement experimental designs allowing measurement of both fission and fusion (including all combinations of $0-2$ flashes and $0-2$ beeps). This would allow measurement of a) unisensory noise in each modality b) prior bias for numerosity and c) prior bias for binding and, with sufficient trials, enable conceptualisation of SIFI perception within a Bayesian framework. That said, due to practical reasons, many researchers may select conditions known to produce the most reliable effects and that can be studied with either fewer participants or fewer trials.

Several findings suggest that the SIFI may tap into a domain-general mechanism utilised across sensory systems, in addition to audition and vision. For instance, a collection of studies show SIFI is associated with postural control and fall-risk (Section 5.3). Furthermore, the SIFI has been extended to other modalities. In the "tap induced flash illusion" (TIFI) pairing a single flash with two concurrent tactile taps results in the perception of two flashes (Violentyev et al., 2005; Wozny et al., 2008). This has been linked with similar processes to the SIFI in terms of

Table 1

Summary of research indicating differences between fission and fusion effects observed in the SIFI. ASD = Autism Spectrum Disorder.

\begin{tabular}{|c|c|c|}
\hline Field & Study & Finding \\
\hline \multirow[t]{3}{*}{ Behavioural } & Chen et al. (2017b) & $\begin{array}{l}\text { Fission effects larger in the periphery than } \\
\text { the centre. Fusion effects larger with } \\
\text { central versus peripheral presentation. }\end{array}$ \\
\hline & $\begin{array}{l}\text { Chatterjee et al. } \\
\text { (2011) }\end{array}$ & $\begin{array}{l}\text { Visually induced flash illusion results in } \\
\text { fission but not fusion effects. }\end{array}$ \\
\hline & Wang et al. (2019) & $\begin{array}{l}\text { Cognitive expectation modulates fission } \\
\text { but not fusion effects }\end{array}$ \\
\hline Development & $\begin{array}{l}\text { Innes-Brown et al. } \\
\text { (2011) }\end{array}$ & $\begin{array}{l}\text { Fission but not fusion significantly stronger } \\
\text { in child group (aged 8-17 years). }\end{array}$ \\
\hline Ageing & $\begin{array}{l}\text { McGovern et al. } \\
\text { (2014) } \\
\text { Parker and } \\
\text { Robinson (2018) }\end{array}$ & $\begin{array}{l}\text { Fission but not fusion effects are stronger in } \\
\text { older versus younger adults. }\end{array}$ \\
\hline Amblyopia & $\begin{array}{l}\text { Narinesingh et al. } \\
\text { (2017) }\end{array}$ & $\begin{array}{l}\text { Patients were more susceptible to fission } \\
\text { and less susceptible to fusion. }\end{array}$ \\
\hline ASD & Bao et al. (2017) & $\begin{array}{l}\text { Adults with ASD show similar fission but } \\
\text { more fusion responses compared with } \\
\text { controls. }\end{array}$ \\
\hline Brain damage & $\begin{array}{l}\text { Bolognini et al. } \\
\text { (2016) }\end{array}$ & $\begin{array}{l}\text { Fusion stronger in patients with unilateral } \\
\text { neglect compared with controls. }\end{array}$ \\
\hline $\begin{array}{l}\text { Brain } \\
\text { stimulation }\end{array}$ & $\begin{array}{l}\text { Bolognini et al. } \\
\text { (2011) }\end{array}$ & $\begin{array}{l}\text { Occipital stimulation interferes with fission } \\
\text { but not fusion. }\end{array}$ \\
\hline
\end{tabular}

sensory dominance for temporal processing (Bresciani et al., 2006; Philippi et al., 2008) as well as neural mechanisms (Lange et al., 2011; van Erp et al., 2014). The SIFI also has a less researched, unimodal, visual counterpart; the Visually Induced Flash Illusion (VIFI), in which presenting a single flash in one location with two consecutive flashes in a separate location results in the perception of the single flash occurring twice (Apthorp et al., 2013; Chatterjee et al., 2011; Leonards and Singer, 1997). It has also been shown that similar Bayesian models can account for both SIFI and VIFI effects, however the tendency to integrate is higher in the SIFI (Beierholm, 2007). Together, these findings show promising support for the idea that the SIFI provides an insight into general multisensory function, rather than audiovisual integration specifically.

If the SIFI can be used to gauge clinically relevant differences in sensory integration, a core question is whether these mechanisms can be trained. Findings suggest that SIFI susceptibility can be shaped through training in psychophysical tasks (Setti et al., 2014), exercise (Masaki et al., 2001; O'Brien et al., 2020, 2017), balance control (Merriman et al., 2015), musical training (Bidelman, 2016) and perhaps even the urbanity of the lived environment (Hirst et al., under review ${ }_{\mathrm{a}}$ ). This poses the possibility that the SIFI could be used as a simple outcome measure for improving the efficiency of multisensory integration. However, given that the participants in these studies were predominantly older adults, and that findings from young adults suggest no change in SIFI susceptibility from training (Powers et al., 2016; Rosenthal et al., 2009), more research is required before prescribing the SIFI as a modifiable outcome measure for multisensory integration. Remaining questions in the field of training include identifying whether discrepant findings in training-related psychophysical tasks result from differing tasks (simultaneity judgements versus TOJ), differing populations (younger versus older adults respectively), or individual differences in the baseline width of the TBW and/or training susceptibility. An essential question is also whether training benefits are retained at longer follow-up intervals.

The nature of the causal link between SIFI perception, cognitive function and clinical conditions and its direction is currently unknown. It is possible that healthy cognition promotes more efficient SIFI perception, alternatively multisensory integration might facilitate healthy cognition e.g. by enhancing learning and memory (Shams and Seitz, 2008). It is also possible that a bidirectional relationship exists. Given that hearing and vision are known predictors of cognitive function in later life (Chen et al., 2017a; Loughrey et al., 2018) it is important to understand the directionality of these effects as this will help determine whether interventions should target multisensory integration itself to promote healthy cognition across the life-course. This goal will be achieved in the near future through large-scale longitudinal studies such as TILDA.

To promote harmonisation across studies, here we discussed the influence of stimulus parameters and propose directions for future research using the SIFI. Illusory fission effects are most prominent when visual stimuli are presented in the periphery and within $100 \mathrm{~ms}$ of one another. Based on the reviewed literature showing stimulus intensity and sensory ability systematically alter SIFI susceptibility, we recommend that, where possible, future research methods attempt to control for stimulus intensity and timing based on individual sensory ability. Furthermore, because SIFI susceptibility is influenced by the ability to perceive two sequential stimuli in vision and audition (Shams et al., 2005b), studies should include conditions where accuracy for judging two unisensory stimuli can be measured. Interestingly, the SIFI does not appear to be modulated by spatial proximity - perhaps due to the temporal nature of the task or because the illusion is not constrained to the multisensory properties of neurones in the SC (Stein and Stanford, 2008). It is likely that spatial congruence does enhance the illusion, however, to a lower degree than congruence/similarity in time and content (flash and beep), hence requiring a large experimental power to be detected. In any case, the robustness of the illusion to spatial disparity 
means that the precise localisation of auditory and visual stimuli is not critical for inducing the SIFI.

Although the SIFI clearly has potential as a research tool, further research is required before it can be considered as a standard clinical measure. For instance, it is not yet known exactly how many illusory trials are required to obtain a robust effect. However, promisingly, the SIFI protocol included in the aforementioned TILDA project has only two trials per condition, and findings have shown the measured effects are influenced by factors that would be predicted based on more standard experimental findings (Hirst et al., 2019b). This has important implications for assessing multisensory function in groups where prolonged testing may not be possible. A second question is how many SOAs are optimal for measuring the TBW. Manipulating the range of SOAs tested in the SIFI has helped elucidate differences between several clinical subgroups (Fig. 4). However, since implementing multiple SOAs could also influence the ability to update perceptual priors through experience researchers should take this into account, particularly when making clinical comparisons. Thus, future research should disentangle these effects to enable a concise interpretation of the SIFI in clinical and non-clinical contexts.

\section{Conclusions}

In the past 20 years the SIFI has been used by over 100 studies, indicating its popularity and usefulness as a research tool. The results from these studies suggest several conclusions. First, the SIFI reflects optimal integration, best modelled within a Bayesian causal inference framework. Second, fission effects in the SIFI arise from early interactions between primary sensory cortices. Third, the SIFI might measure domain-general sensory integration and thus provide a useful tool to assess clinical differences in perception, postural control and cognitive function. The next steps to be taken in research using the SIFI are to identify the directionality of the relationship between the SIFI and cognition, understand the mixed results from clinical studies and understand the factors modulating fission and fusion effects in the SIFI. Thus, while the first 20 years of research into the SIFI have helped us to elucidate the nature and mechanisms of healthy and pathological multisensory perception, the next 20 years are likely to be just as, if not more, insightful.

\section{Funding statement}

This work was supported by the Health Research Board, Ireland; Grant reference ILP-PHR-2017-014.

\section{Declaration of Competing Interest}

The authors report no declarations of interest.

\section{Acknowledgements}

The authors would like to thank Albert Chung at UCLA and Amy Mason at UCC for their assistance in gathering relevant literature for this article.

\section{References}

Aagten-Murphy, D., Cappagli, G., Burr, D., 2014. Musical training generalises across modalities and reveals efficient and adaptive mechanisms for reproducing temporal intervals. Acta Psychol. (Amst). 147, 25-33. https://doi.org/10.1016/j. actpsy.2013.10.007.

Adams, W.J., 2016. The development of audio-visual integration for temporal judgements. PLoS Comput. Biol. 12, 1-17. https://doi.org/10.1371/journal. pcbi.1004865.

Alais, D., Burr, D., 2004. The ventriloquist effect results from near-optimal bimodal integration. Curr. Biol. 14, 257-262. https://doi.org/10.1016/S0960-9822(04) 00043-0.
Amedi, A., Hofstetter, S., Maidenbaum, S., Heimler, B., 2017. Task selectivity as a comprehensive principle for brain organization. Trends Cogn. Sci. 21, 307-310. https://doi.org/10.1016/j.tics.2017.03.007.

Andersen, T.S., Tiippana, K., Sams, M., 2004. Factors influencing audiovisual fission and fusion illusions. Cogn. Brain Res. 21, 301-308. https://doi.org/10.1016/j. cogbrainres.2004.06.004.

Apthorp, D., Alais, D., Boenke, L.T., 2013. Flash illusions induced by visual, auditory, and audiovisual stimuli. J. Vis. 13, 1-15. https://doi.org/10.1167/13.5.3.

Arden, G.B., Wolf, J.E., Messiter, C., 2003. Electrical activity in visual cortex associated with combined auditory and visual stimulation in temporal sequences known to be associated with a visual illusion. Vision Res. 43, 2469-2478. https://doi.org/ 10.1016/S0042-6989(03)00437-1.

Balz, J., 2018. Neurophysiological and Biochemical Markers of Multisensory Processing in Schizophrenia and Healthy Adults. Freien Universität Berlin.

Balz, J., Keil, J., Roa Romero, Y., Mekle, R., Schubert, F., Aydin, S., Ittermann, B., Gallinat, J., Senkowski, D., 2016a. GABA concentration in superior temporal sulcus predicts gamma power and perception in the sound-induced flash illusion. Neuroimage 125, 724-730. https://doi.org/10.1016/j.neuroimage.2015.10.087.

Balz, J., Romero, Y.R., Keil, J., Krebber, M., Niedeggen, M., Gallinat, J., Senkowski, D., 2016b. Beta/gamma oscillations and event-related potentials indicate aberrant multisensory processing in schizophrenia. Front. Psychol. 7, 1-12. https://doi.org/ 10.3389/fpsyg.2016.01896.

Bao, V.A., Doobay, V., Mottron, L., Collignon, O., Bertone, A., 2017. Multisensory integration of low-level information in Autism Spectrum Disorder: measuring susceptibility to the flash-beep illusion. J. Autism Dev. Disord. 47, 2535-2543. https://doi.org/10.1007/s10803-017-3172-7.

Baron-Cohen, S., Burt, L., Smith-Laittan, F., Harrison, J., Bolton, P., 1996. Synaesthesia: prevalence and familiality. Perception 25, 1073-1079. https://doi.org/10.1068/ p251073.

Bauer, A.K.R., Debener, S., Nobre, A.C., 2020. Synchronisation of neural oscillations and cross-modal influences. Trends Cogn. Sci. 24, 481-495. https://doi.org/10.1016/j. tics.2020.03.003.

Beauchamp, M.S., 2005. See me, hear me, touch me: multisensory integration in lateral occipital-temporal cortex. Curr. Opin. Neurobiol. 15, 145-153. https://doi.org/ 10.1016/j.conb.2005.03.011.

Beauchamp, M.S., Argall, B.D., Bodurka, J., Duyn, J.H., Martin, A., 2004. Unraveling multisensory integration: patchy organization within human STS multisensory cortex. Nat. Neurosci. 7, 1190-1192. https://doi.org/10.1038/nn1333.

Beierholm, U.R., 2007. Bayesian Modeling of Sensory Cue Combinations. California Institute of Technology. https://doi.org/10.7907/K89B-XW75.

Bhattacharya, J., Shams, L., Shimojo, S., 2002. Sound-induced illusory flash perception: role of gamma band responses. Neuroreport 13, 1727-1730.

Bidelman, G.M., 2016. Musicians have enhanced audiovisual multisensory binding: experience-dependent effects in the double-flash illusion. Exp. Brain Res. 234, 3037-3047. https://doi.org/10.1007/s00221-016-4705-6.

Bidelman, G.M., Heath, S., 2018. Enhanced temporal binding of audiovisual information in the bilingual brain. Biling. Lang. Cogn. 1-11. https://doi.org/10.1017/ S1366728918000408.

Bizley, J.K., Shinn-Cunningham, B.G., Lee, A.K.C., 2012. Nothing is irrelevant in a noisy world: sensory illusions reveal obligatory within-and across-modality integration. J. Neurosci. 32, 13402-13410. https://doi.org/10.1523/JNEUROSCI.2495-12.2012.

Bolognini, N., Rossetti, A., Casati, C., Mancini, F., Vallar, G., 2011. Neuromodulation of multisensory perception: a tDCS study of the sound-induced flash illusion. Neuropsychologia 49, 231-237. https://doi.org/10.1016/j. neuropsychologia.2010.11.015.

Bolognini, N., Convento, S., Fusaro, M., Vallar, G., 2013. The sound-induced phosphene illusion. Exp. Brain Res. 231, 469-478. https://doi.org/10.1007/s00221-013-37111.

Bolognini, N., Convento, S., Casati, C., Mancini, F., Brighina, F., Vallar, G., 2016. Multisensory integration in Hemianopia and Unilateral Spatial Neglect: evidence from the sound induced flash illusion. Neuropsychologia 87, 134-143.

Botvinick, M.M., Cohen, J., 1998. Rubber hands 'feel' touch that eyes see. Nature 391. https://doi.org/10.1038/35784, 756-756.

Botvinick, M.M., Braver, T.S., Barch, D.M., Carter, C.S., Cohen, J.D., 2001. Conflict monitoring and cognitive control. Psychol. Rev. 108, 624-652. https://doi.org/ 10.1037/0033-295X.108.3.624.

Brang, D., Williams, L.E., Ramachandran, V.S., 2012. Grapheme-color synesthetes show enhanced crossmodal processing between auditory and visual modalities. Cortex 48 , 630-637. https://doi.org/10.1016/j.cortex.2011.06.008.

Bresciani, J.-P., Dammeier, F., Ernst, M.O., 2006. Vision and touch are automatically integrated for the perception of sequences of events. J. Vis. 6, 554-564. https://doi. org $/ 10.1167 / 6.5 .2$

Brighina, F., Bolognini, N., Maccora, S., Indovino, S., Cosentino, G., Vallar, G., Fierro, B., 2014. Cortical excitability in migraine: new evidence by sound-induced flash illusions and transcranial direct current stimulation of visual cortex. Clin. Neurophysiol. 125, S288. https://doi.org/10.1016/S1388-2457(14)50943-1.

Brighina, F., Bolognini, N., Cosentino, G., Maccora, S., Paladino, P., Baschi, R., Vallar, G., Fierro, B., 2015. Visual cortex hyperexcitability in migraine in response to soundinduced flash illusions. Neurology 84. https://doi.org/10.1212/ WNL.0000000000001584.

Bronstein, A.M., 2016. Multisensory integration in balance control. Handbook of Clinical Neurology, pp. 57-66. https://doi.org/10.1016/B978-0-444-63437-5.00004-2.

Calvert, G.A., Campbell, R., Brammer, M.J., 2000. Evidence from functional magnetic resonance imaging of crossmodal binding in the human heteromodal cortex. Curr. Biol. 10, 649-657. https://doi.org/10.1016/S0960-9822(00)00513-3. 
Campos, J., Ramkhalawansingh, R., Pichora-Fuller, M.K., 2018. Hearing, self-motion perception, mobility, and aging. Hear. Res. 369, 42-55. https://doi.org/10.1016/j heares.2018.03.025.

Cecere, R., Rees, G., Romei, V., 2015. Individual differences in alpha frequency drive crossmodal illusory perception. Curr. Biol. 25, 231-235. https://doi.org/10.1016/j. cub.2014.11.034.

Chan, J.S., Kaiser, J., Brandl, M., Matura, S., Prvulovic, D., Hogan, M., Naumer, M., 2015 Expanded temporal binding windows in people with mild cognitive impairment. Curr. Alzheimer Res. 12, 61-68. https://doi.org/10.2174/ 1567205012666141218124744.

Chan, J.S., Langer, A., Kaiser, J., 2016. Temporal integration of multisensory stimuli in autism spectrum disorder: a predictive coding perspective. J. Neural Transm. 123, 917-923. https://doi.org/10.1007/s00702-016-1587-5.

Chan, J.S., Wibral, M., Wollstadt, P., Stawowsky, C., Brandl, M., Helbling, S., Naumer, M., Kaiser, J., 2017. Predictive coding over the lifespan: increased reliance on perceptual priors in older adults - a magnetoencephalography and dynamic causal modelling study. bioRxiv. https://doi.org/10.1101/178095.

Chan, J.S., Connolly, S.K., Setti, A., 2018. The number of stimulus-onset asynchronies affects the perception of the sound-induced flash illusion in young and older adults. Multisens. Res. 31, 175-190. https://doi.org/10.1163/22134808-00002605.

Chatterjee, G., Wu, D., Sheth, B.R., 2011. Phantom flashes caused by interactions across visual space. J. Vis. 11, 1-17. https://doi.org/10.1167/11.2.14.Introduction.

Chen, S.P., Bhattacharya, J., Pershing, S., 2017a. Association of vision loss with cognition in older adults. JAMA Ophthalmol. 135, 963-970. https://doi.org/10.1001/ jamaophthalmol.2017.2838.

Chen, Y.C., Lewis, T.L., Shore, D.I., Maurer, D., 2017b. Early binocular input is critical for development of audiovisual but not visuotactile simultaneity perception. Curr. Biol. 27, 583-589. https://doi.org/10.1016/j.cub.2017.01.009.

Clavagnier, S., Falchier, A., Kennedy, H., 2004. Long-distance feedback projections to area V1: implications for multisensory integration, spatial awareness, and visual consciousness. Cogn. Affect. Behav. Neurosci. 4, 117-126. https://doi.org/10.3758/ CABN.4.2.117.

Cloke, J.M., Nguyen, R., Chung, B.Y.T., Wasserman, D.I., De Lisio, S., Kim, J.C., Bailey, C D.C., Winters, B.D., 2016. A novel multisensory integration task reveals robust deficits in rodent models of schizophrenia: converging evidence for remediation via nicotinic receptor stimulation of inhibitory transmission in the prefrontal cortex. J. Neurosci. 36, 12570-12585. https://doi.org/10.1523/jneurosci.1628-16.2016.

Colavita, F.B., 1974. Human sensory dominance. Percept. Psychophys. 16, 409-412. https://doi.org/10.3758/BF03203962.

Cosentino, G., Talamanca, S., Aprile, M., Maccora, S., Baschi, R., Pilati, L., Di Marco, S. Fierro, B., Brighina, F., 2015. O047. The sound-induced flash illusions reveal visual cortex hyperexcitability in cluster headache. J. Headache Pain 16, 1-2. https://doi. org/10.1186/1129-2377-16-S1-A92.

Crosse, M.J., Foxe, J.J., Molholm, S., 2019. Developmental recovery of impaired multisensory processing in Autism and the cost of switching sensory modality. BioRxiv. https://doi.org/10.1101/565333.

Cuppini, C., Magosso, E., Bolognini, N., Vallar, G., Ursino, M., 2014. A neurocomputational analysis of the sound-induced flash illusion. Neuroimage 92 248-266. https://doi.org/10.1016/j.neuroimage.2014.02.001.

de Haas, B., Kanai, R., Jalkanen, L., Rees, G., 2012. Grey matter volume in early human visual cortex predicts proneness to the sound-induced flash illusion. Proc. R. Soc. B Biol. Sci. 279, 4955-4961. https://doi.org/10.1098/rspb.2012.2132.

Dehaene, S., Piazza, M., Pinel, P., Cohen, L., 2003. Three parietal circuits for number processing. Cogn. Neuropsychol. 20, 487-506. https://doi.org/10.1080/ 02643290244000239.

Deloss, D.J., Andersen, G.J., 2015. Aging, spatial disparity, and the sound-induced flash illusion. PLoS One 10. https://doi.org/10.1371/journal.pone.0143773.

DeLoss, D.J., Pierce, R.S., Anderson, G.J., 2013. Multisensory integration, aging, and the sound-induced flash illusion. Psychol. Aging 28, 802-812. https://doi.org/10.1037/ a0033289.

Di Marco, S., Cosentino, G., Pilati, L., Baschi, R., Maccora, S., Aprile, M., Brighina, F., Fierro, B., 2015. The visual cortical excitability in pediatric migraine as tested by sound-induced flash illusions. J. Headache Pain 16, A75. https://doi.org/10.1186/ 1129-2377-16-S1-A75.

Diederich, A., Colonius, H., 2004. Bimodal and trimodal multisensory enhancement: effects of stimulus onset and intensity on reaction time. Percept. Psychophys. 66, 1388-1404. https://doi.org/10.3758/BF03195006.

Eckert, M., Kamdar, N., Chang, C., 2008. A cross-modal system linking primary auditory and visual cortices. Hum. Brain Mapp. 29, 848-857. https://doi.org/10.1002/ hbm.20560.A.

Engel, A.K., Fries, P., Singer, W., 2001. Dynamic predictions: oscillations and synchrony in top-down processing. Nat. Rev. Neurosci. 2, 704-716. https://doi.org/10.1038/ 35094565.

Ernst, M.O., 2008. Multisensory integration: a late bloomer. Curr. Biol. 18, 519-521. https://doi.org/10.1016/j.cub.2008.05.002.

Ernst, M.O., 2010. From independence to fusion: a comprehensive model for multisensory integration. J. Vis. https://doi.org/10.1167/5.8.650.

Ernst, M.O., Banks, M.S., 2002. Humans integrate visual and haptic information in a statistically optimal fashion. Nature 415, 429-433. https://doi.org/10.1038/ 415429a.

Ernst, M.O., Bülthoff, H.H., 2004. Merging the senses into a robust percept. Trends Cogn. Sci. (Regul. Ed.) 8, 162-169. https://doi.org/10.1016/j.tics.2004.02.002.

Falchier, A., Clavagnier, S., Barone, P., Kennedy, H., 2002. Anatomical evidence of multimodal integration in primate striate cortex. J. Neurosci. 22, 5749-5759. https://doi.org/10.1523/jneurosci.22-13-05749.2002.
Ferri, F., Venskus, A., Fotia, F., Cooke, J., Romei, V., 2018. Higher proneness to multisensory illusions is driven by reduced temporal sensitivity in people with high schizotypal traits. Conscious. Cogn. 65, 263-270. https://doi.org/10.1016/j. concog.2018.09.006.

Forster, B., Cavina-Pratesi, C., Aglioti, S.M., Berlucchi, G., 2002. Redundant target effect and intersensory facilitation from visual-tactile interactions in simple reaction time. Exp. Brain Res. 143, 480-487. https://doi.org/10.1007/s00221-002-1017-9.

Foss-Feig, J.H., Kwakye, L.D., Cascio, C.J., Burnette, C.P., Kadivar, H., Stone, W.L., Wallace, M.T., 2010. An extended multisensory temporal binding window in autism spectrum disorders. Exp. Brain Res. 203, 381-389. https://doi.org/10.1007/s00221010-2240-4.

Gerson, L.W., Jarjoura, D., Mccord, G., 1989. Risk of imbalance in elderly people with impaired hearing or vision. Age Ageing 18, 31-34. https://doi.org/10.1093/ageing/ 18.1.31.

Gieseler, A., Tahden, M.A.S., Thiel, C.M., Colonius, H., 2018. Does hearing aid use affect audiovisual integration in mild hearing impairment? Exp. Brain Res. 236, 1161-1179. https://doi.org/10.1007/s00221-018-5206-6.

Gondan, M., Niederhaus, B., Rösler, F., Röder, B., 2005. Multisensory processing in the redundant-target effect: a behavioral and event-related potential study. Percept. Psychophys. 67, 713-726. https://doi.org/10.3758/BF03193527.

Gori, M., Del Viva, M., Sandini, G., Burr, D.C., 2008. Young children do not integrate visual and haptic form information. Curr. Biol. 18, 694-698. https://doi.org/ 10.1016/j.cub.2008.04.036.

Gyorgy, B., Xiao-Jing, W., 2012. Mechanisms of gamma oscillations. Annu. Rev. Neurosci. 6, 2166-2171. https://doi.org/10.1021/nl061786n.Core-Shell.

Hamilton, R.H., Wiener, M., Drebing, D.E., Branch Coslett, H., 2013. Gone in a flash: manipulation of audiovisual temporal integration using transcranial magnetic stimulation. Front. Psychol. 4, 1-7. https://doi.org/10.3389/fpsyg.2013.00571.

Haß, K., Sinke, C., Reese, T., Roy, M., Wiswede, D., Dillo, W., Szycik, G.R., Oranje, B., 2017. Enlarged temporal integration window in schizophrenia indicated by the double-flash illusion. Cogn. Neurophsychiatry 22, 145-158. https://doi.org/ 10.1080/13546805.2017.1287693.

Hay, J.C., Pick, H.L., Ikeda, K., 1965. Visual capture produced by prism spectacles. Psychon. Sci. 2, 215-216. https://doi.org/10.3758/bf03343413.

Hernández, B., Setti, A., Kenny, R.A., Newell, F.N., 2019. Individual differences in ageing, cognitive status, and sex on susceptibility to the sound-induced flash illusion: a large-scale study. Psychol. Aging 34, 978-990. https://doi.org/10.1037/ pag0000396.

Herrmann, C.S., Fründ, I., Lenz, D., 2010. Human gamma-band activity: a review on cognitive and behavioral correlates and network models. Neurosci. Biobehav. Rev. 34, 981-992. https://doi.org/10.1016/j.neubiorev.2009.09.001.

Hirst, R.J., Cragg, L., Allen, H.A., 2018a. Vision dominates audition in adults but not children: a meta-analysis of the Colavita effect. Neurosci. Biobehav. Rev. 94, 286-301. https://doi.org/10.1016/j.neubiorev.2018.07.012.

Hirst, R.J., Stacey, J.E., Cragg, L., Stacey, P.C., Allen, H.A., 2018b. The threshold for the McGurk effect in audio-visual noise decreases with development. Sci. Rep. 8, 1-12. https://doi.org/10.1038/s41598-018-30798-8.

Hirst, R.J., Kicks, E., Allen, H.A., Cragg, L., 2019a. Cross-modal interference-control is reduced in childhood but maintained in aging: a lifespan study of stimulus- and response-interference in cross-modal and unimodal Stroop tasks. J. Exp. Psychol. Hum. Percept. Perform. 45, 553.

Hirst, R.J., Setti, A., Kenny, R., Newell, F.N., 2019b. Age-related sensory decline mediates the Sound-Induced Flash Illusion: evidence for reliability weighting models of multisensory perception. Sci. Rep. 9 https://doi.org/10.1038/s41598-019-559015.

Hirst, R.J., Setti, A., Boyle, R., Whelan, R., Knight, S., O’Connor, J., Williamson, W., McMorrow, J., Fagan, A.J., Meaney, J.F., Kenny, R.A., De Looze, C., Newell, F.N., under review ${ }_{\mathrm{a}}$ Grey matter volume in the right Angular Gyrus is associated with differential patterns of multisensory integration with ageing.

Hirst, R.J., Cassarino, M., Kenny, R.A., Newell, F.N., Setti, A., under review b. Urban and rural environments differentially shape susceptibility to the Sound-Induced Flash Illusion in ageing.

Hirst, R.J., Setti, A., De Looze, C., Akuffo, K.O., Peto, T., Kenny, R.A., Newell, F.N. The effect of eye disease, cataract surgery and hearing aid use on multisensory integration in ageing. Cortex,In Press, 2020.

Hirst, R.J., Setti, A., Kenny, R.A., Newell, F.N., in prep. Multisensory integration is associated with Executive Function and Memory but not Processing Speed in ageing.

Holt, K.R., Haavik, H., Lee, A.C.L., Murphy, B., Elley, C.R., 2016. Effectiveness of chiropractic care to improve sensorimotor function associated with falls risk in older people: a Randomized Controlled Trial. J. Manipulative Physiol. Ther. 39, 267-278. https://doi.org/10.1016/j.jmpt.2016.02.003.

Howard, I., Templeton, W.B., 1966. Human Spatial Orientation. Wiley, London.

Hutmacher, F., 2019. Why is there so much more research on vision than on any other sensory modality? Front. Psychol. 10 https://doi.org/10.3389/fpsyg.2019.02246.

Innes-Brown, H., Crewther, D., 2009. The impact of spatial incongruence on an auditoryvisual illusion. PLoS One 4. https://doi.org/10.1371/journal.pone.0006450.

Innes-Brown, H., Barutchu, A., Shivdasani, M.N., Crewther, D.P., 2011. Susceptibility to the flash-beep illusion is increased in children compared to adults. Dev. Sci. 14 1089-1099. https://doi.org/10.1111/j.1467-7687.2011.01059.x.

Innes-Brown, H., Barutchu, A., Crewther, D.P., 2013. Neural responses in parietal and occipital areas in response to visual events are modulated by prior multisensory stimuli. PLoS One 8. https://doi.org/10.1371/journal.pone.0084331.

Ito, Y., Sato, R., Tamai, Y., Hiryu, S., Uekita, T., Kobayasi, K.I., 2019. Auditory-induced visual illusions in rodents measured by spontaneous behavioural response. Sci. Rep. 9, 1-3. https://doi.org/10.1038/s41598-019-55664-z. 
Kadunce, D.C., Vaughan, W.J., Wallace, M.T., Stein, B.E., 2001. The influence of visual and auditory receptive field organization on multisensory integration in the superior colliculus. Exp. Brain Res. 139, 303-310. https://doi.org/10.1007/s002210100772.

Kaiser, M., Senkowski, D., Busch, N.A., Balz, J., Keil, J., 2019. Single trial prestimulus oscillations predict perception of the sound-induced flash illusion. Sci. Rep. 9, 1-8. https://doi.org/10.1038/s41598-019-42380-x.

Kamke, M.R., Vieth, H.E., Cottrell, D., Mattingley, J.B., 2012. Parietal disruption alters audiovisual binding in the sound-induced flash illusion. Neuroimage 62, 1334-1341. https://doi.org/10.1016/j.neuroimage.2012.05.063.

Kawakami, S., Uono, S., Otsuka, S., Zhao, S., Toichi, M., 2018. Everything has its time: narrow temporal windows are associated with high levels of autistic traits via weaknesses in multisensory integration. J. Autism Dev. Disord. 0 (0) https://doi.org/ 10.1007/s10803-018-3762-Z

Keane, B.P., Rosenthal, O., Chun, N.H., Shams, L., 2010. Audiovisual integration in high functioning adults with autism. Res. Autism Spectr. Disord. 4, 276-289. https://doi. org/10.1016/j.rasd.2009.09.015.

Keil, J., 2020. Double flash illusions: current findings and future directions. Front. Neurosci. Percept. Sci. https://doi.org/10.3389/fnins.2020.00298.

Keil, J., Senkowski, D., 2017. Individual alpha frequency relates to the sound-induced flash illusion. Multisens. Res. 30, 565-578. https://doi.org/10.1163/2213480800002572 .

Keil, J., Senkowski, D., 2018. Neural oscillations orchestrate multisensory processing. Neuroscientist 24, 609-626. https://doi.org/10.1177/1073858418755352.

Keil, J., Müller, N., Hartmann, T., Weisz, N., 2014. Prestimulus beta power and phase synchrony influence the sound-induced flash illusion. Cereb. Cortex 24, 1278-1288. https://doi.org/10.1093/cercor/bhs409.

Klimesch, W., 2012. Alpha-band oscillations, attention, and controlled access to stored information. Trends Cogn. Sci. 16, 606-617. https://doi.org/10.1016/j tics.2012.10.007.

Körding, K.P., Beierholm, U., Ma, W.J., Quartz, S., Tenenbaum, J.B., Shams, L., 2007. Causal inference in multisensory perception. PLoS One 2. https://doi.org/10.1371/ journal.pone.0000943.

Kumpik, D.P., Roberts, H.E., King, A.J., Bizley, J.K., 2014. Visual sensitivity is a stronger determinant of illusory processes than auditory cue parameters in the sound-induced flash illusion. J. Vis. 14 https://doi.org/10.1167/14.7.12, 12-12.

Kyrdalen, I.L., Thingstad, P., Sandvik, L., Ormstad, H., 2019. Associations between gait speed and well-known fall risk factors among community-dwelling older adults. Physiother. Res. Int. 24, 1-6. https://doi.org/10.1002/pri.1743.

Lambourne, K., Audiffren, M., Tomporowski, P.D., 2010. Effects of acute exercise on sensory and executive processing tasks. Med. Sci. Sports Exerc. 42, 1396-1402. https://doi.org/10.1249/MSS.0b013e3181cbee11.

Lange, J., Oostenveld, R., Fries, P., 2011. Perception of the touch-induced visual doubleflash illusion correlates with changes of rhythmic neuronal activity in human visua and somatosensory areas. Neuroimage 54, 1395-1405. https://doi.org/10.1016/j. neuroimage.2010.09.031.

Lange, J., Oostenveld, R., Fries, P., 2013. Reduced occipital alpha power indexes enhanced excitability rather than improved visual perception. J. Neurosci. 33, 3212-3220. https://doi.org/10.1523/JNEUROSCI.3755-12.2013.

Lange, J., Keil, J., Schnitzler, A., van Dijk, H., Weisz, N., 2014. The role of alpha oscillations for illusory perception. Behav. Brain Res. 271, 294-301. https://doi.org/ 10.1016/j.bbr. 2014.06.015.

Laufs, H., Krakow, K., Sterzer, P., Eger, E., Beyerle, A., Salek-Haddadi, A., Kleinschmidt, A., 2003. Electroencephalographic signatures of attentional and cognitive default modes in spontaneous brain activity fluctuations at rest. Proc. Natl. Acad. Sci. U. S. A. 100, 11053-11058. https://doi.org/10.1073/pnas.1831638100.

Lee, H., Noppeney, U., 2011. Long-term music training tunes how the brain temporally binds signals from multiple senses. Proc. Natl. Acad. Sci. U. S. A. 108, 20295-20296. https://doi.org/10.1073/pnas.1115267108.

Lee, H., Noppeney, U., 2014. Music expertise shapes audiovisual temporal integration windows for speech, sinewave speech, and music. Front. Psychol. 5, 1-9. https://doi org/10.3389/fpsyg. 2014.00868.

Leonards, U., Singer, W., 1997. Selective temporal interactions between processing streams with differential sensitivity for colour and luminance contrast. Vision Res. 37, 1129-1140. https://doi.org/10.1016/S0042-6989(96)00264-7.

Loughrey, D.G., Kelly, M.E., Kelley, G.A., Brennan, S., Lawlor, B.A., 2018. Association of age-related hearing loss with cognitive function, cognitive impairment, and dementia A systematic review and meta-analysis. JAMA Otolaryngol. - Head Neck Surg. 144, 115-126. https://doi.org/10.1001/jamaoto.2017.2513.

Lovelace, C.T., Stein, B.E., Wallace, M.T., 2003. An irrelevant light enhances auditory detection in humans: a psychophysical analysis of multisensory integration in stimulus detection. Cogn. Brain Res. 17, 447-453. https://doi.org/10.1016/S0926 6410(03)00160-5.

Maccora, S., Mannina, C., Bolognini, N., Paladino, P., Baschi, R., Cosentino, G., Fierro, B., Vallar, G., Brighina, F., 2015. 0069. Menstrual cycle affects cortical excitability differently in females with migraine and in healthy controls: a new perspective by cross modal sound induced flash illusions. J. Headache Pain 16, A141. https://doi. org/10.1186/1129-2377-16-S1-A141.

Maccora, S., Giglia, G., Bolognini, N., Cosentino, G., Gangitano, M., Salemi, G., Brighina, F., 2019. Cathodal occipital tDCS is unable to modulate the sound induced flash illusion in migraine. Front. Hum. Neurosci. 13, 1-5. https://doi.org/10.3389/ fnhum.2019.00247.

Malpeli, J.G., Lee, D., Baker, F.H., 1996. Laminar and retinotopic organization of the macaque lateral geniculate nucleus: magnocellular and parvocellular magnification functions. J. Comp. Neurol. 375, 363-377. https://doi.org/10.1002/(SICI)10969861(19961118)375:3<363::AID-CNE2>3.0.CO;2-0.
Marco, E.J., Barett, L., Hinkley, N., Hill, S.S., 2011. Sensory processing in Autism: a review of Neurophysiologic findings. Pediatr. Res. 69, 48R-54R. https://doi.org/ 10.1203/PDR.0b013e3182130c54.

Masaki, H., Tanaka, H., Takasawa, N., Yamazaki, K., 2001. Error-related brain potentials elicited by vocal errors. Neuroreport 12, 1851-1855. https://doi.org/10.1097/ 00001756-200107030-00018.

Maunsell, J.H., Ghose, G.M., Assad, J.A., Mcadams, C.J., Boudreau, C.E., Noerager, B.D., 1999. Visual response latencies of magnocellular and parvocellular LGN neurons in macaque monkeys. Vis. Neurosci. 16, 1-14. https://doi.org/10.1017 S0952523899156177.

McCormick, D., Mamassian, P., 2008. What does the illusory-flash look like? Vision Res. 48, 63-69. https://doi.org/10.1016/j. visres.2007.10.010.

McGovern, D.P., Roudaia, E., Newell, F.N., Roach, N.W., 2016b. Perceptual learning shapes multisensory causal inference via two distinct mechanisms. Sci. Rep. 6, 24673. https://doi.org/10.1038/srep24673.

McGovern, D.P., Roudaia, E., Stapleton, J., McGinnity, T.M., Newell, F.N., 2014. The sound-induced flash illusion reveals dissociable age-related effects in multisensory integration. Front. Aging Neurosci. 6, 1-9. https://doi.org/10.3389/ fnagi.2014.00250.

McGovern, D.P., Astle, A.T., Clavin, S.L., Newell, F.N., 2016a. Task-specific transfer of perceptual learning across sensory modalities. Curr. Biol. 26, R20-R21. https://doi. org/10.1016/j.cub.2015.11.048.

McGurk, H., MacDonald, J., 1976. Hearing lips and seeing voices. Nature 264, 746-748. https://doi.org/10.1038/264746a0.

Mercier, M.R., Foxe, J.J., Fiebelkorn, I.C., Butler, J.S., Schwartz, T.H., Molholm, S., 2013. Auditory-driven phase reset in visual cortex: human electrocorticography reveals mechanisms of early multisensory integration. Neuroimage 79, 19-29. https://doi. org/10.1016/j.neuroimage.2013.04.060.

Mercier, M.R., Molholm, S., Fiebelkorn, I.C., Butler, J.S., Schwartz, T.H., Foxe, J.J., 2015. Neuro-oscillatory phase alignment drives speeded multisensory response times: an electro-corticographic investigation. J. Neurosci. 35, 8546-8557. https://doi.org/ 10.1523/JNEUROSCI.4527-14.2015.

Meredith, M.A., Stein, B.E., 1996. Spatial determinants of multisensory integration in cat superior colliculus neurons. J. Neurophysiol. 75, 1843-1857. https://www.citeulikearticle-id:411558.

Meredith, M.A., Nemitz, J.W., Stein, B.E., 1987. Determinants of multisensory integration in superior colliculus neurons. I. Temporal factors. J. Neurosci. 7 , 3215-3229. https://doi.org/10.1523/JNEUROSCI.07-10-03215.1987.

Merriman, N.A., Whyatt, C., Setti, A., Craig, C., Newell, F.N., 2015. Successful balance training is associated with improved multisensory function in fall-prone older adults. Comput. Human Behav. 45, 192-203. https://doi.org/10.1016/j.chb.2014.12.017.

Meylan, R.V., Murray, M.M., 2007. Auditory-visual multisensory interactions attenuate subsequent visual responses in humans. Neuroimage 35, 244-254. https://doi.org/ 10.1016/j.neuroimage.2006.11.033.

Michail, G., Keil, J., 2018. High cognitive load enhances the susceptibility to non-speech audiovisual illusions. Sci. Rep. 8, 1-11. https://doi.org/10.1038/s41598-01830007-6.

Mishra, J., Martinez, A., Sejnowski, T.J., Hillyard, S.A., 2007. Early cross-modal interactions in auditory and visual cortex underlie a sound-induced visual illusion. J. Neurosci. 27, 4120-4131. https://doi.org/10.1523/JNEUROSCI.4912-06.2007.

Mishra, J., Martinez, A., Hillyard, S.A., 2008. Cortical processes underlying the soundinduced flash fusion. Brain Res. 1242, 102-115. https://doi.org/10.1016/j. brainres.2008.05.023.

Moro, S.S., Steeves, J.K.E., 2012. No Colavita effect: equal auditory and visual processing in people with one eye. Exp. Brain Res. 216, 367-373. https://doi.org/10.1007/ s00221-011-2940-4.

Moro, S.S., Steeves, J.K.E., 2013. No Colavita effect: increasing temporal load maintains equal auditory and visual processing in people with one eye. Neurosci. Lett. 556, 186-190. https://doi.org/10.1016/j.neulet.2013.09.064.

Moro, S.S., Steeves, J.K.E., 2018. Normal temporal binding window but no soundinduced flash illusion in people with one eye. Exp. Brain Res. 236, 1825-1834. https://doi.org/10.1007/s00221-018-5263-x.

Murray, M.M., Lewkowicz, D.J., Amedi, A., Wallace, M.T., 2016a. Multisensory processes: a balancing act across the lifespan. Trends Neurosci. 39, 567-579. https:// doi.org/10.1016/j.tins.2016.05.003.

Murray, M.M., Thelen, A., Thut, G., Romei, V., Martuzzi, R., Matusz, P.J., 2016b. The multisensory function of the human primary visual cortex. Neuropsychologia 83 , 161-169. https://doi.org/10.1016/j.neuropsychologia.2015.08.011.

Narinesingh, C., Goltz, H.C., Wong, A.M.F., 2017. Temporal binding window of the sound-induced flash illusion in amblyopia. Investig. Opthalmology Vis. Sci. 58, 1442. https://doi.org/10.1167/iovs.16-21258.

Nava, E., Pavani, F., 2013. Changes in sensory dominance during childhood: converging evidence from the Colavita effect and the sound-induced flash illusion. Child Dev. 84, 604-616. https://doi.org/10.1111/j.1467-8624.2012.01856.x.

Nelson, W.T., Hettinger, L.J., Cunningham, J.A., Brickman, B.J., Haas, M.W., McKinley, R.L., 1998. Effects of localized auditory information on visual target detection performance using a helmet-mounted display. Hum. Factors 40, 452-460. https://doi.org/10.1518/001872098779591304.

Neufeld, J., Sinke, C., Zedler, M., Emrich, H.M., Szycik, G.R., 2012. Reduced audio-visual integration in synaesthetes indicated by the double-flash illusion. Brain Res. 1473, 78-86. https://doi.org/10.1016/j.brainres.2012.07.011.

Newell, F.N., Mitchell, K.J., 2016. Multisensory integration and cross-modal learning in synaesthesia: a unifying model. Neuropsychologia $88,140-150$. https://doi.org/ 10.1016/j.neuropsychologia.2015.07.026. 
Noel, J., De Niear, M., Van der Burg, E., Wallace, M.T., 2016. Audiovisual simultaneity judgment and rapid recalibration throughout the lifespan. PLoS One 11, 1-14. https://doi.org/10.1371/journal.pone.0161698.

Noesselt, T., Bergmann, D., Hake, M., Heinze, H.J., Fendrich, R., 2008. Sound increases the saliency of visual events. Brain Res. 1220, 157-163. https://doi.org/10.1016/j. brainres.2007.12.060.

O'Brien, J., Ottoboni, G., Tessari, A., Setti, A., 2017. One bout of open skill exercise improves cross-modal perception and immediate memory in healthy older adults who habitually exercise. PLoS One 12, 1-16. https://doi.org/10.1371/journal. pone.0178739.

O’Brien, J., Ottoboni, G., Tessari, A., Setti, A., 2020. Multisensory perception, verbal, visuo-spatial, and motor working memory modulation after a single open- or closedskill exercise session in children. BioRxiv. https://doi.org/10.1101/ 2020.01.29.924563.

O'Hare, L., 2017. Multisensory integration in migraine: recent developments. Multisens. Res. 30, 549-563. https://doi.org/10.1163/22134808-00002570.

Odegaard, B., Shams, L., 2016. The brain's tendency to bind audiovisual signals is stable but not general. Psychol. Sci. 27, 583-591. https://doi.org/10.1177/ 0956797616628860.

Odegaard, B., Shams, L., 2017. The relationship between audiovisual binding tendencies and prodromal features of Schizophrenia in the general population. Clin. Psychol. Sci. 5, 733-741. https://doi.org/10.1177/2167702617704014.

Odegaard, B., Wozny, D.R., Shams, L., 2016. The effects of selective and divided attention on sensory precision and integration. Neurosci. Lett. 614, 24-28. https:// doi.org/10.1016/j.neulet.2015.12.039.

Odgaard, E.C., Arieh, Y., Marks, L.E., 2004. Brighter noise: sensory enhancement of perceived loudness by concurrent visual stimulation. Cogn. Affect. Behav. Neurosci. 4, 127-132. https://doi.org/10.3758/CABN.4.2.127.

Olson, I.R., Gatenby, J.C., Gore, J.C., 2002. A comparison of bound and unbound audiovisual information processing in the human cerebral cortex. Cogn. Brain Res. 14, 129-138. https://doi.org/10.1016/S0926-6410(02)00067-8.

Parker, J.L., Robinson, C.W., 2018. Changes in multisensory integration across the lifespan. Psychol. Aging 33, 545-558. https://doi.org/10.1037/pag0000244.

Pérez-Bellido, A., Ernst, M.O., Soto-Faraco, S., López-Moliner, J., 2015. Visual limitations shape audio-visual integration. J. Vis. 15, 5. https://doi.org/10.1167/15.14.5.

Philippi, T.G., van Erp, J.B.F., Werkhoven, P.J., 2008. Multisensory temporal numerosity judgment. Brain Res. 1242, 116-125. https://doi.org/10.1016/j. brainres.2008.05.056.

Postmes, L., Sno, H.N., Goedhart, S., van der Stel, J., Heering, H.D., de Haan, L., 2014. Schizophrenia as a self-disorder due to perceptual incoherence. Schizophr. Res. 152, 41-50. https://doi.org/10.1016/j.schres.2013.07.027.

Powers, A.R., Hillock, A.R., Wallace, M.T., 2009. Perceptual training narrows the temporal window of multisensory binding. J. Neurosci. 29, 12265-12274. https:// doi.org/10.1523/JNEUROSCI.3501-09.2009.

Powers, A.R., Hillock-Dunn, A., Wallace, M.T., 2016. Generalization of multisensory perceptual learning. Sci. Rep. 6, 1-9. https://doi.org/10.1038/srep23374.

Prince, F., Corriveau, H., Hébert, R., Winter, D.A., 1997. Gait in the elderly. Gait Posture 5, 128-135.

Puschmann, S., Thiel, C.M., 2017. Changed crossmodal functional connectivity in older adults with hearing loss. Cortex 86, 109-122. https://doi.org/10.1016/j. cortex.2016.10.014.

Rammsayer, T.H., Buttkus, F., Altenmüller, E., 2012. Musicians do better than nonmusicians in both auditory and visual timing tasks. Music Percept. 30, 85-96. https://doi.org/10.1525/mp.2012.30.1.85.

Rock, I., Victor, J., 1964. Vision and touch: an experimentally created conflict between the two senses. Science 143, 594-596. https://doi.org/10.1126/ science.143.3606.594.

Rockland, K.S., Ojima, H., 2003. Multisensory convergence in calcarine visual areas in macaque monkey. Int. J. Psychophysiol. 50, 19-26. https://doi.org/10.1016/S0167 8760(03)00121-1.

Rohe, T., Ehlis, A.-C., Noppeney, U., 2018. The neural dynamics of causal inference in perception. bioRxiv. https://doi.org/10.1101/504845.

Roseboom, W., Kawabe, T., Nishida, S., 2013. The cross-modal double flash illusion depends on featural similarity between cross-modal inducers. Sci. Rep. 3, 1-5. https://doi.org/10.1038/srep03437.

Rosenthal, O., Shimojo, S., Shams, L., 2009. Sound-induced flash illusion is resistant to feedback training. Brain Topogr. 21, 185-192. https://doi.org/10.1007/s10548009-0090-9.

Schwedt, T.J., 2013. Multisensory integration in migraine. Curr. Opin. Neurol. 26, 248-253. https://doi.org/10.1097/WCO.0b013e328360edb1.

Seghier, M.L., 2013. The angular gyrus: multiple functions and multiple subdivisions Neuroscientist 19, 43-61. https://doi.org/10.1177/1073858412440596.

Senkowski, D., Talsma, D., Herrmann, C.S., Woldorff, M.G., 2005. Multisensory processing and oscillatory gamma responses: effects of spatial selective attention. Exp. Brain Res. 166, 411-426. https://doi.org/10.1007/s00221-005-2381-z.

Setti, A., Chan, J.S., 2011. Familiarity of objects affects susceptibility to the soundinduced flash illusion. Neurosci. Lett. 492, 19-22. https://doi.org/10.1016/j. neulet.2011.01.042.

Setti, A., Burke, K.E., Kenny, R.A., Newell, F.N., 2011. Is inefficient multisensory processing associated with falls in older people? Exp. Brain Res. 209, 375-384. https://doi.org/10.1007/s00221-011-2560-z.

Setti, A., Stapleton, J., Leahy, D., Walsh, C., Kenny, R.A., Newell, F.N., 2014. Improving the efficiency of multisensory integration in older adults: audio-visual temporal discrimination training reduces susceptibility to the sound-induced flash illusion. Neuropsychologia 61, 259-268. https://doi.org/10.1016/j.

neuropsychologia.2014.06.027.
Shams, L., 2012. Early integration and Bayesian Causal Inference in multisensory perception. In: Murray, M.M., Wallace, M.T. (Eds.), The Neural Basis of Multisensory Processes. CRC Press/Taylor \& Francis, Boca Raton (FL), pp. 1-35. https://doi.org/ 10.1152/jn.00497.2006.

Shams, L., Beierholm, U., 2011. Humans' multisensory perception, from integration to segregation, follows bayesian inference. Sensory Cue Integration. Oxford University Press, pp. 251-262. https://doi.org/10.1093/acprof:oso/ 9780195387247.003.0013.

Shams, L., Seitz, A.R., 2008. Benefits of multisensory learning. Trends Cogn. Sci. 12, 411-417. https://doi.org/10.1016/j.tics.2008.07.006.

Shams, L., Kamitani, Y., Shimojo, S., 2000. What you see is what you hear. Nature 408, 788. https://doi.org/10.1038/35048669.

Shams, L., Kamitani, C.A.Y., Thompson, S., Shimojo, S., 2001. Sound alters visual evoked potentials in humans. Neuroreport 12, 1-4.

Shams, L., Kamitani, Y., Shimojo, S., 2002. Visual illusion induced by sound. Cogn. Brain Res. 14, 147-152. https://doi.org/10.1016/S0926-6410(02)00069-1.

Shams, L., Iwaki, S., Chawla, A., Bhattacharya, J., 2005a. Early modulation of visual cortex by sound: an MEG study. Neurosci. Lett. 378, 76-81. https://doi.org/ 10.1016/j.neulet.2004.12.035.

Shams, L., Ma, W.J., Beierholm, U., 2005b. Sound-induced flash illusion as an optimal percept. Neuroreport 16, 1923-1927. https://doi.org/10.1097/01. wnr.0000187634.68504.bb.

Simner, J., Mulvenna, C., Sagiv, N., Tsakanikos, E., Witherby, S.A., Fraser, C., Scott, K., Ward, J., 2006. Synaesthesia: the prevalence of atypical cross-modal experiences. Perception 35, 1024-1033. https://doi.org/10.1068/p5469.

Singer, W., Gray, C.M., 1995. Visual feature integration and the temporal correlation hypothesis. Annu. Rev. Neurosci. 18, 555-586. https://doi.org/10.1146/annurev. ne.18.030195.003011.

Spence, C., 2013. Just how important is spatial coincidence to multisensory integration? Evaluating the spatial rule. Ann. N. Y. Acad. Sci. 1296, 31-49. https://doi.org/ $10.1111 /$ nyas.12121.

Spence, Charles, 2019. Evaluating the spatial rule of multisensory integration: when exactly does spatial coincidence matter. In: Cheng, T., Deroy, O., Spence, C. (Eds.), Spatial Senses: Philosophy of Perception in an Age of Science. Routedge, New York, USA, pp. 284-306. https://doi.org/10.4324/9781315146935.

Stapleton, J., Setti, A., Doheny, E.P., Kenny, R.A., Newell, F.N., 2014. A standing posture is associated with increased susceptibility to the sound-induced flash illusion in fallprone older adults. Exp. Brain Res. 232, 423-434. https://doi.org/10.1007/s00221013-3750-7.

Stein, B.E., Meredith, A.M., 1993. The Merging of the Senses. MIT Press, London.

Stein, B.E., Stanford, T.R., 2008. Multisensory integration: current issues from the perspective of the single neuron. Nat. Rev. Neurosci. 9 https://doi.org/10.1038/ nrn2377, 406-406.

Stein, B.E., Meredith, M.A., Huneycutt, W.S., McDade, L., 1989. Behavioral indices of multisensory integration: orientation to visual cues is affected by auditory stimuli. J. Cogn. Neurosci. 1, 12-24. https://doi.org/10.1162/jocn.1989.1.1.12.

Stein, B.E., London, N., Wilkinson, L.K., Price, D.D., 1996. Enhancement of perceived visual intensity by auditory stimuli: a psychophysical analysis. J. Cogn. Neurosci. 8, 497-506. https://doi.org/10.1162/jocn.1996.8.6.497.

Sterzer, P., Adams, R.A., Fletcher, P., Frith, C., Lawrie, S.M., Muckli, L., Petrovic, P., Uhlhaas, P., Voss, M., Corlettj, P.R., 2018. The predictive coding account of psychosis. Biol. Psychiatry 84, 634-643. https://doi.org/10.1016/j biopsych.2018.05.015.

Stevenson, R.A., Zemtsov, R.K., Wallace, M.T., 2012. Individual differences in the multisensory temporal binding window predict susceptibility to audiovisual illusions. J. Exp. Psychol. Hum. Percept. Perform. 38, 1517-1529. https://doi.org/ 10.1037/a0027339.Individual.

Stevenson, R.A., Siemann, J.K., Woynaroski, T.G., Schneider, B.C., Eberly, H.E. Camarata, S.M., Wallace, M.T., 2014. Evidence for diminished multisensory integration in Autism Spectrum disorders. J. Autism Dev. Disord. 44, 3161-3167. https://doi.org/10.1007/s10803-014-2179-6.

Takeshima, Y., Gyoba, J., 2013. Complexity of visual stimuli affects visual illusion induced by sound. Vision Res. 91, 1-7. https://doi.org/10.1016/j. visres.2013.07.013.

Tay, M.A., Poh, M., Tee, L.H., Ismail, N.H., 2015. Normative gait speed and its relation to falls in the community dwelling elderly in Singapore. ECPT Congress 2015 / Physiotherapy 2015. The Chartered Society of Physiotherapy, pp. 1493-1494.

Tremblay, C., Champoux, F., Voss, P., Bacon, B.A., Lepore, F., Théoret, H., 2007. Speech and non-speech audio-visual illusions: a developmental study. PLoS One 2. https:// doi.org/10.1371/journal.pone.0000742.

Valton, V., Karvelis, P., Richards, K.L., Seitz, A.R., Lawrie, S.M., Seriès, P., 2018. Acquisition of visual priors and induced hallucinations in chronic schizophrenia. BioRxiv 18, 1-34. https://doi.org/10.1101/498568.

Van de Cruys, S., Evers, K., van der Hallen, R., van Eylen, L., Boets, B., De-Wit, L., Wagemans, J., 2014. Precise minds in uncertain worlds: predictive coding in autism. Psychol. Rev. 121, 649-675. https://doi.org/10.1037/a0037665.

van Der Smagt, M.J., van Engeland, H., Kemner, C., 2007. Brief report: can you see what is not there? Low-level auditory-visual integration in autism spectrum disorder. J. Autism Dev. Disord. 37, 2014-2019. https://doi.org/10.1007/s10803-006-03460 .

van Erp, J.B.F., Philippi, T.G., Werkhoven, P., 2013. Observers can reliably identify illusory flashes in the illusory flash paradigm. Exp. Brain Res. 226, 73-79. https:// doi.org/10.1007/s00221-013-3413-8.

van Erp, J.B.F., Philippi, T.G., de Winkel, K.N., Werkhoven, P., 2014. Pre- and poststimulus EEG patterns associated with the touch-induced illusory flash. Neurosci. Lett. 562, 79-84. https://doi.org/10.1016/j.neulet.2014.01.010. 
Vanes, L.D., White, T.P., Wigton, R.L., Joyce, D., Collier, T., Shergill, S.S., 2016. Reduced susceptibility to the sound-induced flash fusion illusion in schizophrenia. Psychiatry Res. 245, 58-65. https://doi.org/10.1016/j.psychres.2016.08.016.

Violentyev, A., Shimojo, S., Shams, L., 2005. Touch-induced visual illusion. Neuroreport 16, 1107-1110. https://doi.org/10.1097/00001756-200507130-00015.

Wahn, B., Rohe, T., Gearhart, A., Kingstone, A., Sinnett, S., 2020. Performing a task jointly enhances the sound-induced flash illusion. PsychArxiv Pr. https://doi.org/ 10.31234/osf.io/h3uwq.

Wallace, M.T., Stein, B.E., 1994. Cross-modal synthesis in the midbrain depends on input from cortex. J. Neurophysiol. 71, 429-432.

Wallace, M.T., Woynaroski, T.G., Stevenson, R.A., 2020. Multisensory integration as a window into orderly and disrupted cognition and communication. Annu. Rev. Psychol. 71 https://doi.org/10.1146/annurev-psych-010419-051112.

Wang, A., Sang, H., He, J., Sava-Segal, C., Tang, X., Zhang, M., 2019. Effects of cognitive expectation on sound-induced flash illusion. Perception 48, 1214-1234. https://doi org $/ 10.1177 / 0301006619885796$.

Watkins, S., Shams, L., Tanaka, S., Haynes, J.D., Rees, G., 2006. Sound alters activity in human V1 in association with illusory visual perception. Neuroimage 31, 1247-1256. https://doi.org/10.1016/j.neuroimage.2006.01.016.

Watkins, S., Shams, L., Josephs, O., Rees, G., 2007. Activity in human V1 follows multisensory perception. Neuroimage 37, 572-578. https://doi.org/10.1016/j neuroimage.2007.05.027.

Welch, R.B., Warren, D.H., 1980. Immediate perceptual response to intersensory discrepancy. Psychol. Bull. 88, 638-667.

Welch, R.B., Warren, D.H., 1986. Intersensory interactions. In: Boff, K.R., Kaufman, L., Thomas, J.P. (Eds.), Handbook of Perception and Human Performance. Wiley, New York, pp. 25.1-25.36. https://doi.org/10.1037/0033-2909.88.3.638.
Whittingham, K.M., McDonald, J.S., Clifford, C.W.G., 2014. Synesthetes show normal sound-induced flash fission and fusion illusions. Vision Res. 105, 1-9. https://doi. org/10.1016/j.visres.2014.08.010.

Wilkie, S., Stevens, C., Dean, R., 2008. Psychoacoustic manipulation of the soundinduced illusory flash. In: Kronland-Martinet, R., Ystad, S., Jensen, K. (Eds.), Computer Music Modeling and Retrieval. Sense of Sounds. CMMR 2007. Lecture Notes in Computer Science. Springer, Berlin, Heidelberg. https://doi.org/10.1007/ 978-3-540-85035-9.

Wong, N.A., Rafique, S.A., Kelly, K.R., Moro, S.S., Gallie, B.L., Steeves, J.K.E., 2018 Altered white matter structure in the visual system following early monocular enucleation. Hum. Brain Mapp. 39, 133-144. https://doi.org/10.1002/hbm.23831.

Wozny, D.R., Beierholm, U.R., Shams, L., 2008. Human trimodal perception follows optimal statistical inference. J. Vis. 8, 24. https://doi.org/10.1167/8.3.24.

Yalachkov, Y., Bergmann, H.J., Soydaş, D., Buschenlange, C., Fadai Motlagh, L.Y., Naumer, M.J., Kaiser, J., Frisch, S., Behrens, M., Foerch, C., Gehrig, J., 2019. Cognitive impairment in Multiple Sclerosis is reflected by increased susceptibility to the sound-induced flash illusion. Front. Neurol. 10, 1-10. https://doi.org/10.3389/ fneur.2019.00373.

Yang, W., Chu, B., Yang, J., Yu, Y., Wu, J., Yu, S., 2014. Elevated audiovisual temporal interaction in patients with migraine without aura. J. Headache Pain 15, 1-10. https://doi.org/10.1186/1129-2377-15-44.

Zhang, S., Xu, W., Zhu, Y., Tian, E., Kong, W., 2020. Impaired Multisensory Integration Predisposes the Elderly People to Fall: A Systematic Review, p. 14. https://doi.org/ 10.3389/fnins.2020.00411. 